\title{
Mach Cutoff Analysis and Results from NASA's Farfield Investigation of No-boom Thresholds
}

\author{
Larry J. Cliatt II, ${ }^{1}$ Michael A. Hill, ${ }^{2}$ Edward A. Haering Jr. ${ }^{3}$ \\ NASA Armstrong Flight Research Center, Edwards, California, 93523
}

In support of the ongoing effort by the National Aeronautics and Space Administration (NASA) to bring supersonic commercial travel to the public, the NASA Armstrong Flight Research Center and the NASA Langley Research Center, in partnership with other industry organizations and academia, conducted a flight research experiment to analyze acoustic propagation in the Mach cutoff shadow zone. The effort was conducted in the fall of 2012 and named the Farfield Investigation of No-boom Thresholds (FaINT). The test helped to build a dataset that will go toward further understanding of the unique acoustic propagation characteristics below Mach cutoff altitude. FaINT was able to correlate sonic boom noise levels measured below cutoff altitude with precise airplane flight conditions, potentially increasing the accuracy over previous studies.

A NASA F-18B airplane made supersonic passes such that its Mach cutoff caustic would be at varying distances above a linear 60-microphone, 7375 -ft $(2247.9 \mathrm{~m})$ long array. A TG-14 motor glider equipped with a microphone on its wing-tip also attempted to capture the same sonic boom waves above ground, but below the Mach cutoff altitude.

This paper identified an appropriate metric for sonic boom waveforms in the Mach cutoff shadow zone called Perceived Sound Exposure Level; derived an empirical relationship between Mach cutoff flight conditions and noise levels in the shadow zone; validated a safe cutoff altitude theory presented by previous studies; analyzed the sensitivity of flight below Mach cutoff to unsteady atmospheric conditions and realistic aircraft perturbations; and demonstrated the ability to record sonic boom measurements over $5000 \mathrm{ft}(1524.0 \mathrm{~m})$ above ground level, but below Mach cutoff altitude.

a

$\mathrm{a}_{\mathrm{O}}$ AAMP AFRC AGL

ASEL

$\mathrm{B} \& \mathrm{~K}$

BNC

BREN

FaINT

GPS

$\mathrm{H}_{\mathrm{P}}$

IRIG

ISO

$\mathrm{L}$

LDS

\section{Nomenclature}

$$
\begin{aligned}
& =\text { speed of sound, } \mathrm{ft} / \mathrm{s}(\mathrm{m} / \mathrm{s}) \\
& =\text { speed of sound } \text { at aircraft altitude, } \mathrm{ft} / \mathrm{s}(\mathrm{m} / \mathrm{s}) \\
& =\text { Airborne Acoustic Measurement Platform } \\
& =\text { Armstrong Flight Research Center, Edwards, California } \\
& =\text { above ground level } \\
& =\text { A-weighted Sound Exposure Level } \\
& =\text { Brüel \& Kjær } \\
& =\text { Bayonet Neill-Concelman } \\
& =\text { Bare Reactor Experiment, Nevada } \\
& =\text { Farfield Investigation of No-boom Thresholds } \\
& =\text { global positioning system } \\
& =\text { pressure altitude, ft (m) } \\
& =\text { inter-rage instrumentation group time code } \\
& =\text { International Organization of Standards } \\
& =\text { signal length, ft }(\mathrm{m}) \\
& =\text { Ling Dynamic Systems }
\end{aligned}
$$

\footnotetext{
${ }^{1}$ Aerospace Engineer, Research Aerodynamics \& Propulsion, P.O. Box 273, Edwards, California/MS 2228, AIAA non-member.

${ }^{2}$ Aerospace Engineer, Simulation Engineer, P.O. Box 273, Edwards, California/MS 4840A, AIAA non-member. ${ }^{3}$ Aerospace Engineer, Research Aerodynamics \& Propulsion, P.O. Box 273, Edwards, California/MS 2228, AIAA non-member.
} 


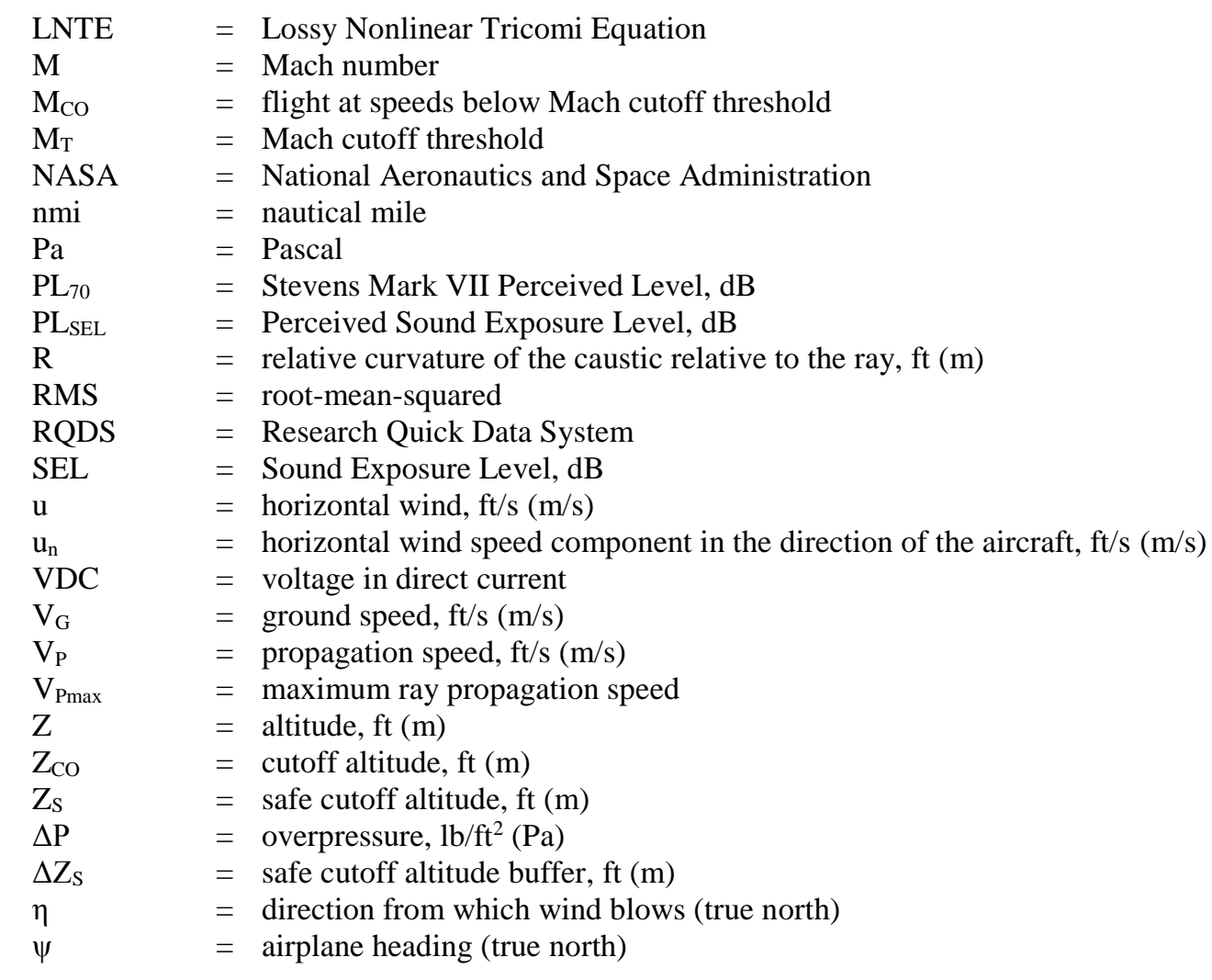

\section{Introduction}

A ACH cutoff flight $\left(\mathrm{M}_{\mathrm{CO}}\right)$ occurs when the sonic boom rays of an airplane refract above the ground. Such a flight can be an approach to sonic boom mitigation. The fastest Mach number for which complete ray refraction will occur above the ground is called the Mach cutoff threshold $\left(\mathrm{M}_{\mathrm{T}}\right)$. The refraction is due to the change in sound propagation speed. As the rays propagate from the airplane to the ground, the speed of propagation $\left(V_{P}\right)$ changes mostly as a function of atmospheric temperature changes. Generally, this change in temperature results in an increase of $\mathrm{V}_{\mathrm{P}}$ as the rays approach the ground. At the altitude of complete refraction, referred to as the cutoff altitude ( $\left.Z_{\mathrm{CO}}\right)$, there is a coalescing of rays on a line called a caustic. If the rays do not reach the ground, there is no traditional sonic boom. Instead, below the caustic there is a field of subsonic sound waves with exponentially decreasing magnitude (evanescent waves) ${ }^{1}$ called the "shadow zone." With enough distance the evanescent waves can attenuate to an infinitesimal level, resulting in little or no disturbance on the ground (Fig. 1). Because of this phenomenon $\mathrm{M}_{\mathrm{CO}}$ has been referred to as "boomless flight."1 It should be noted that the evanescent waves caused by this phenomenon are still classified as sonic booms.

Since $\mathrm{M}_{\mathrm{CO}}$ can result in an insignificant disturbance on the ground, it can be used as a method to fly at supersonic speeds without the annoyance of normal, louder sonic booms. In the ongoing effort by the air travel industry to bring commercial supersonic flight to fruition, future operations will need to produce much quieter sonic booms than modern supersonic airplanes. The two most notable models are (1) boomless flight and (2) boom minimization through aircraft design. This paper will focus on the former. Boomless flight consists of flying an airplane below $\mathrm{M}_{\mathrm{T}}$ so that no sonic boom rays reach the ground at all. With practical $\mathrm{M}_{\mathrm{T}}$ speeds up to Mach $1.3,{ }^{2}$ the speeds could exceed current commercial airplane operations by over $30 \%$, while producing practically no noise on the ground.

For flight below $\mathrm{M}_{\mathrm{T}}$ to be a viable model there needs to be a comprehensive, validated understanding of the noise levels in the shadow zone. Changes in sonic boom noise regulations will be dependent on the ability to keep noise levels below a yet-to-be-defined threshold. 


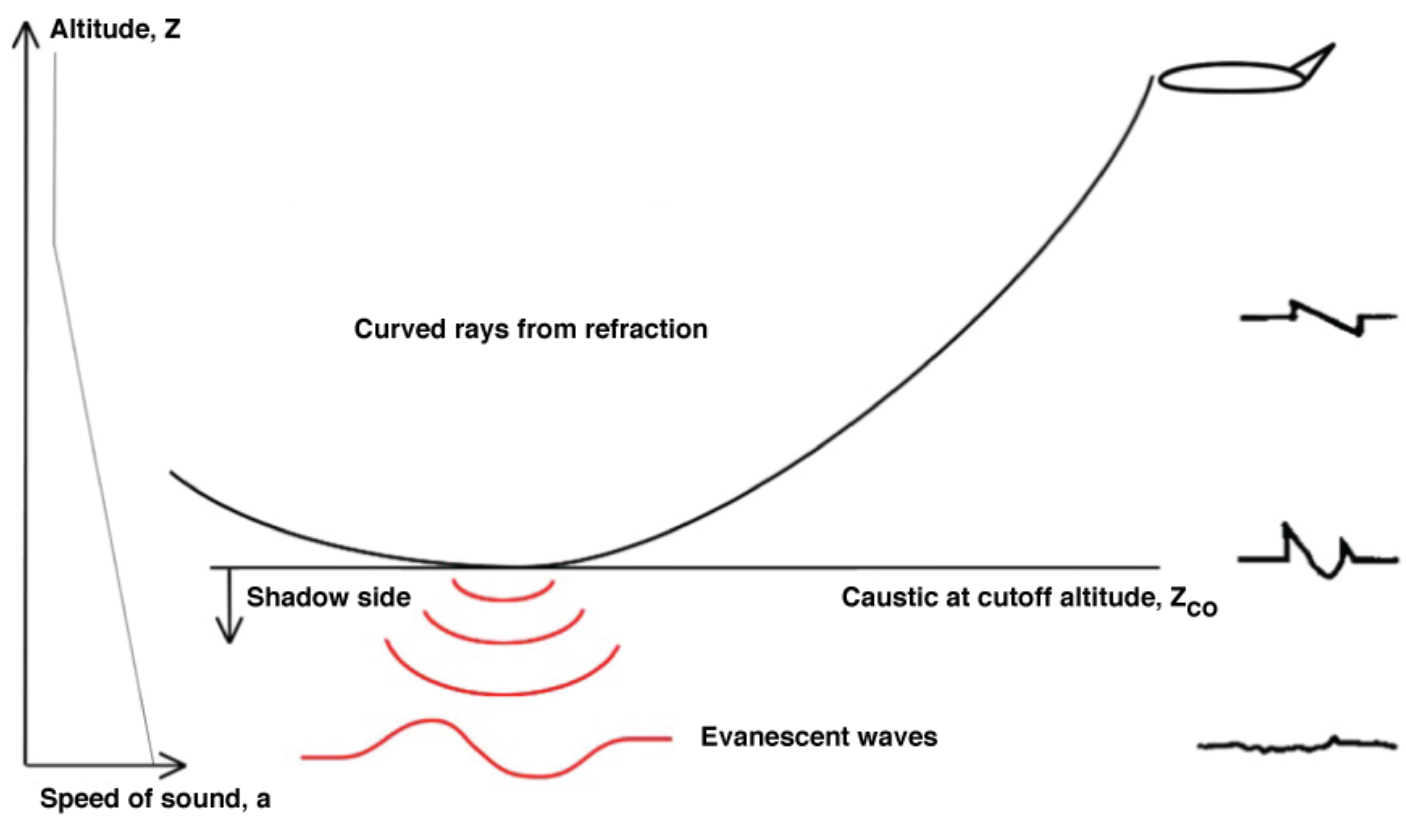

Figure 1. Schematic of Mach cutoff occurrence.

\section{A. Background}

Maglieri ${ }^{2}$ presents an extensive literature review of Mach cutoff research. However, because sonic booms in the shadow zone (where geometrical acoustics predicts no signal) have been challenging to analyze due to their complex propagation, ${ }^{3}$ a vast majority of past research focused on theory. The most notable study with measured data was from the 1970 Bare Reactor Experiment, Nevada (BREN) tower flights. ${ }^{4,5}$ Fig. 2 shows some of the results. The study pioneered $\mathrm{M}_{\mathrm{CO}}$ research. However, as is evident in Fig. 2, the relationship between $\mathrm{M}_{\mathrm{T}}$ and sonic boom levels measured on the ground was unclear. The measured data in Fig. 2 show scattered pressure levels in the typical $\mathrm{M}_{\mathrm{CO}}$ range.

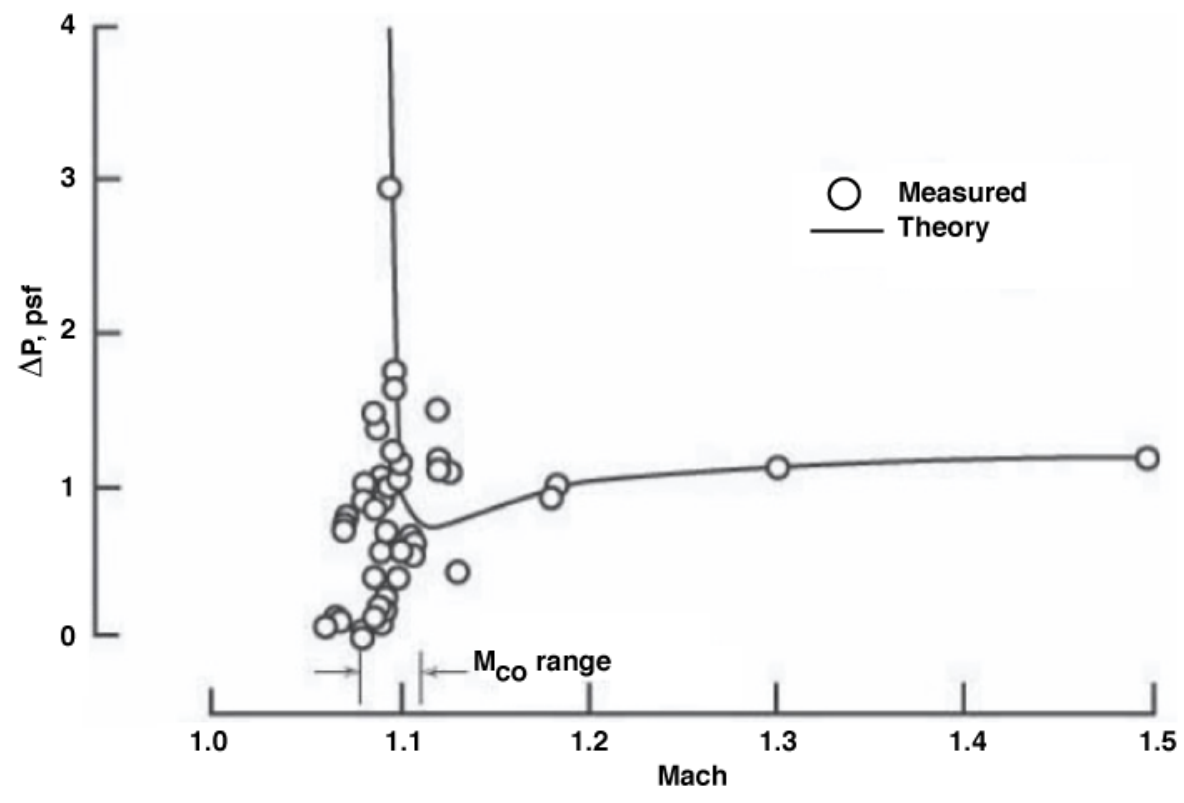

Figure 2. BREN tower study; variation of overpressure ( $\Delta \mathrm{P})$ with Mach number. ${ }^{5}$

The key goals of the Farfield Investigation of No-boom Thresholds (FaINT) $\mathrm{M}_{\mathrm{COS}}$ were to develop and execute the methods to measure shadow zone acoustics below $\mathrm{Z}_{\mathrm{CO}}$, and to collect a comprehensive database of the resulting evanescent waves. FaINT attempted to analyze the region where sonic boom evanescent waves attenuate. As shown

American Institute of Aeronautics and Astronautics 
in Fig. 3 the top pressure signature in the figure is from 7000-ft (2133.6-m) AGL, but below the caustic. The bottom pressure signature was measured on the ground. Both measurements are in the shadow zone and the attenuation of the evanescent waves can be seen. The red boxes in the figure emphasize the similar pressure signature characteristics that are evident even $7000 \mathrm{ft}(2133.6 \mathrm{~m})$ apart.

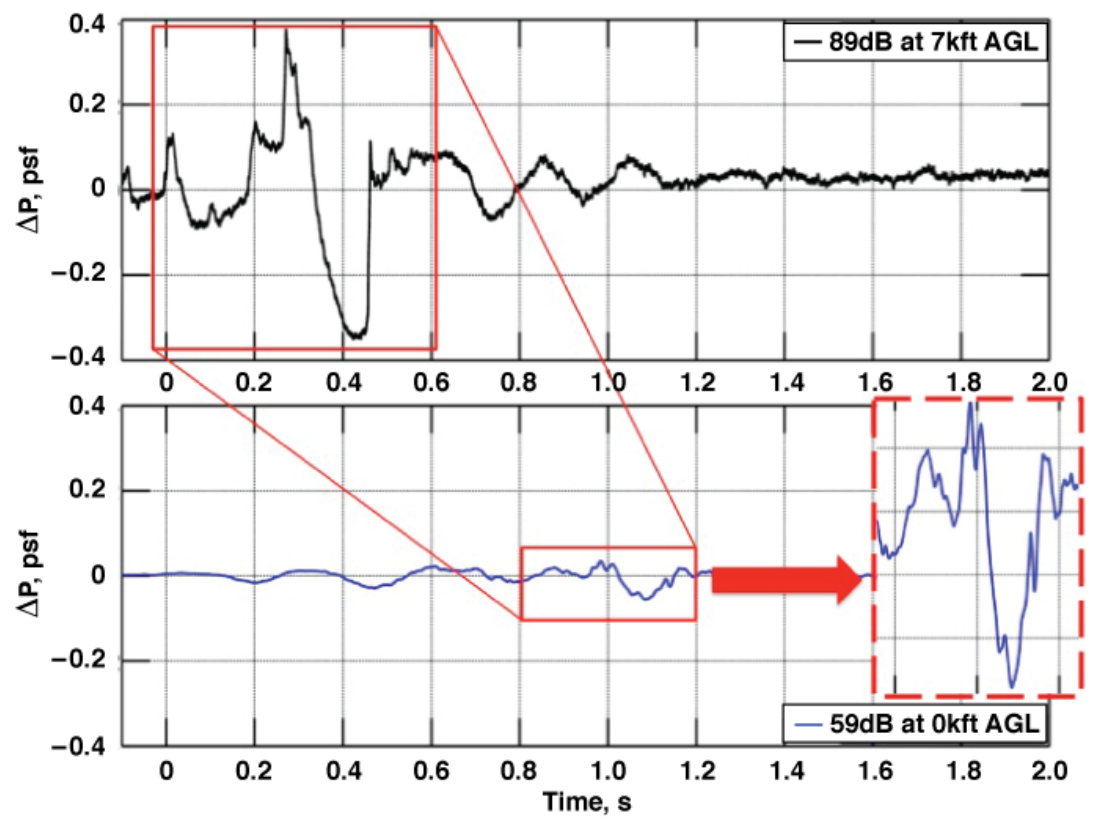

Figure 3. Example of sonic boom pressure signature attenuation with increasing distance from caustic.

The FaINT test was a National Aeronautics and Space Administration (NASA) collaborative effort with several industry partners. It was planned and managed out of the NASA Armstrong Flight Research Center (AFRC) in Edwards, California, USA, while NASA Langley Research Center (Hampton, Virginia, USA) and Wyle (El Segundo, California, USA) provided acoustic propagation expertise. Other partners included The Boeing Company (Chicago, Illinois, USA), Gulfstream Aerospace Corporation (Savannah, Georgia, USA), The Cessna Aircraft Company (Wichita, Kansas, USA), The Pennsylvania State University (University Park, Pennsylvania, USA), The Japan Aerospace Exploration Agency (Chōfu, Tokyo, Japan), and Dassault Aviation (Paris, France); all of which provided invaluable instrumentation and sonic boom field operations proficiency.

Examining acoustic propagation from flight below $\mathrm{M}_{\mathrm{T}}$ will help the aerospace industry understand the full extent and ranges of noises generated by a supersonic aircraft. The ability to predict sound levels below $\mathrm{Z}_{\mathrm{CO}}$ will be critical to the boomless flight commercial travel model. Also, understanding the entire region susceptible to sonic booms caused by supersonic airplanes will be critical in determining target flight profiles for future commercial supersonic airplanes.

This paper focuses on analyzing the change in sonic boom levels as a function of distance from $\mathrm{Z}_{\mathrm{CO}}$ using appropriate metrics for shadow zone pressure signatures; the development of an empirical method of relating Mach cutoff parameters to noise levels measured on the ground, thereby improving the results from previous studies (Fig. 2); modern validation of a theoretical Mach safe cutoff altitude $\left(Z_{S}\right) ; 5$ a sensitivity analysis of flight below Mach cutoff threshold; and a comparison between midfield (far enough from the airplane that the shock structure is mostly constant, but above the atmospheric boundary layer) and ground measurements in the shadow zone.

\section{B. Project Objectives}

One of the project objectives for FaINT was to provide a dataset for validation of future shadow zone computer models and for use in empirical analysis. Existing models like the Lossy Nonlinear Tricomi Equation (LNTE) ${ }^{6}$ developed by The Pennsylvania State University are not practical to use for full sonic boom carpets since they take extensive computing core hours to model single sonic boom rays and have yet to be validated with Mach cutoff data. FaINT will provide a working reference database as more advanced models are developed. Another objective was to determine or develop an appropriate noise metric to characterize the unique waveforms of sonic booms in the shadow zone. Metrics commonly accepted by the sonic boom community, such as Stevens' Mark VII ${ }^{7}$ Perceived Level (PL 70 ) 
and A-weighted Sound Exposure Level (ASEL) were found to be less applicable for the waveform shape of the evanescent waves in the shadow zone. ${ }^{8}$

\section{Flight Objectives}

The success of the test relied heavily on the ability to fly an airplane to produce target $\mathrm{Z}_{\mathrm{CO}}$ levels and place the caustic accurately and precisely above a specific location on a microphone array on the ground. The primary FaINT flight objective was to use airplane flight assets that were already available to NASA to conduct straight and level flight profiles at speeds ranging from Mach 1.12 to 1.18 and at altitudes of 34,000-ft to 40,000-ft (10363.2-m to $12192.0-\mathrm{m}$ ) pressure altitude (Hp). In order to consistently and successfully perform these flight profiles it was required that, while supersonic, the airplane be capable of maintaining a constant heading within 3 degrees and Mach number within a \pm 0.003 tolerance. This restriction would help eliminate off-condition passes, resulting in an aggressive, concise flight phase. It was required that the airplane be capable of performing at least six flight passes per flight. An F-18 airplane (McDonnell Douglas, now The Boeing Company, Chicago, Illinois, USA) was used to satisfy these requirements.

Because atmospheric conditions play a significant role in the propagation of sonic booms, atmospheric soundings from a global positioning system (GPS) radiosonde weather balloon were required prior to each flight for mission planning purposes. Atmospheric soundings were also required at takeoff time for post-flight analysis of sonic boom modeling. For similar reasons it was also a requirement to record meteorological data at ground level.

\section{Test Architecture}

Key FaINT test assets consisted of airplanes and instrumentation on the ground. Ground instrumentation was required to measure sonic boom signatures and atmospheric conditions near the ground. The test included two sets of airplanes: one to produce sonic booms, and the other to record sonic booms in the midfield. Other test elements included flight operations and mission planning efforts.

\section{A. Ground Instrumentation}

The array of ground sensors for FaINT consisted of a linear microphone array, a spiral microphone array, and three weather towers (Fig. 4) all located on the southwest portion of Rogers Dry Lakebed at Edwards Air Force Base, California, USA. There was also a tethered blimp with microphones attached, provided and operated by Cessna, to record measurements more than $2000 \mathrm{ft}(609.6 \mathrm{~m})$ above the ground. However, the blimp and its data are not discussed here because it is beyond the scope of this paper.

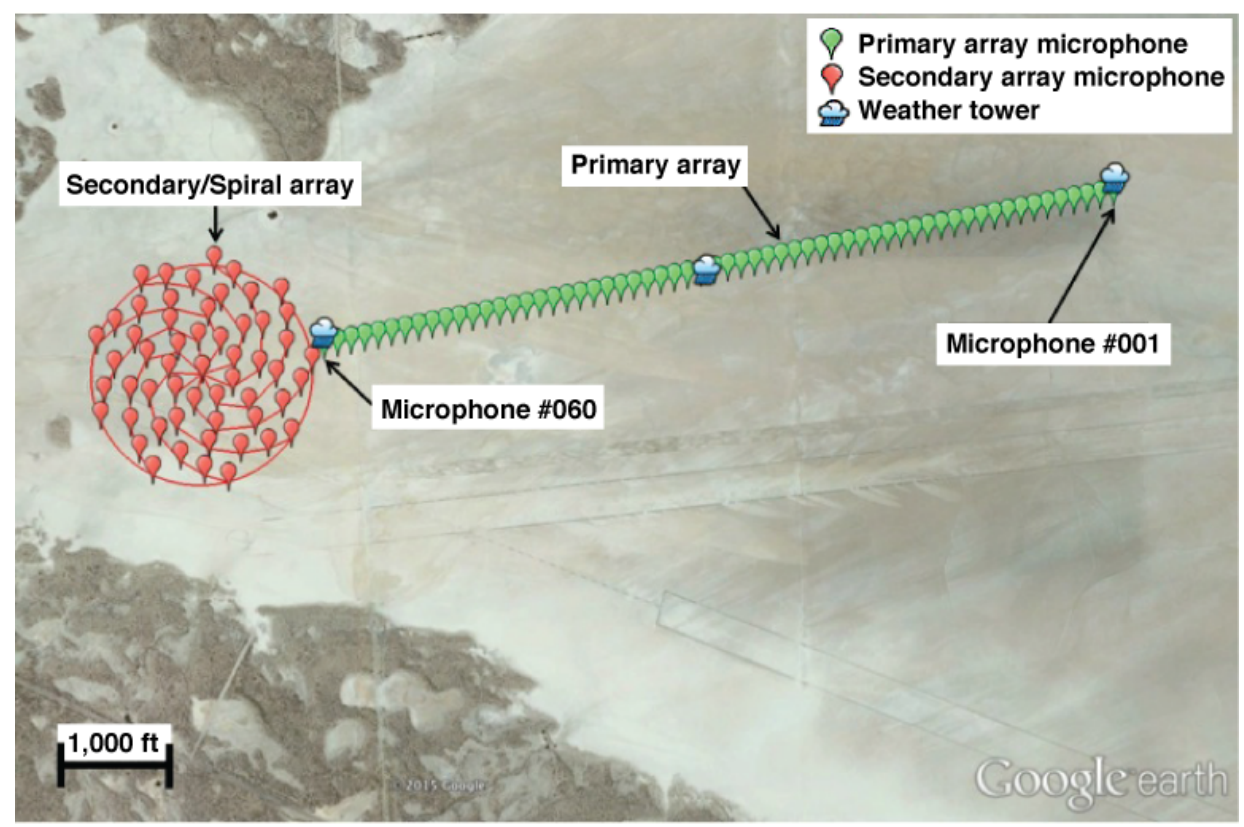

Figure 4. FaINT Mach cutoff ground microphone arrays. 
Rogers Dry Lakebed offered a very hard and obstruction free area. Microphone location measurements discussed in the next section, Section II.A.1, showed that the altitude varied less than one foot over the linear arrays. The spiral array microphones were within $1 / 16$ in. $(1.6 \mathrm{~mm})$ of a flat plane, tilted about one arc minute from level, east side down. The orientations of the arrays were selected based on topography of the lakebed shoreline and the available airspace, most notably the High Altitude Supersonic Corridor.

\section{Ground Microphone Arrays}

The primary microphone array was linear and consisted of 60 microphones spaced $125 \mathrm{ft}(38.1 \mathrm{~m})$ apart along a heading of 79 to 259 degrees from true north in order to be parallel to the airplane flight path. The individual microphones were labeled \#001 through \#060, where \#001 was on the east side of the array and \#060 was on the west side of the array. A spacing of $125 \mathrm{ft}(38.1 \mathrm{~m})$ was chosen as a trade-off between desiring little variation in pressure signature measurements from one microphone to the next due to airplane flight and atmospheric variability as well as desiring as large an array in distance as possible. There were also constraints with the total number of microphones and recording channels available, as well as limitations with the quantity of cables needed and the workforce to deploy, operate, and retrieve the cables and equipment. In all, almost 3 miles $(4.8 \mathrm{~km})$ of seven-conductor microphone cable and over 8 miles $(12.9 \mathrm{~km}$ ) of coaxial Bayonet Neill-Concelman (BNC) cable were used for the linear array. Appropriate cabling was used to ensure that signal attenuation was not a factor considering the extreme distances involved.

On the linear array Brüel \& Kjær (B\&K) (Naerum, Denmark) model 4193 low frequency microphones (without the UC0211 low frequency adapter) were used at 47 locations, and G.R.A.S. Sound and Vibration (Holte, Denmark) model 40AN low frequency microphones were used at 13 locations due to model 4193 availability. The two types of microphones are comparable in sonic boom measurement quality. Cables were deployed at the beginning of the program, and remained deployed in the field for the one-week period. Each B\&K microphone was covered with a hemispherical foam windscreen, and used a B\&K preamplifier model 2669C. Microphones were calibrated pre- and post-flight with a B\&K model 4231 sound calibrator set at $94 \mathrm{~dB}$. The microphone data were adjusted by being given a calibration gain, which was based on the difference between the measured signal root-mean-squared (RMS) and the theoretical calibrator RMS. B\&K model 2690-0S4 Nexus ${ }^{\mathrm{TM}}$ amplifiers were used to raise the maximum signal voltage up to +/- 10VDC. Fifteen Nexus ${ }^{\mathrm{TM}}$ amplifiers were used on groups of four microphones. From the Nexus ${ }^{\mathrm{TM}}$ amplifiers, long BNC cables provided the signals to four analog-to-digital converters and recorders distributed along the array. Three B\&K Ling Dynamic Systems (LDS) Dactron brand model Focus II recorders were used on microphones \#001 through \#029. A National Instruments (Austin, Texas, USA) model 4472 PXI recorder was used for microphones \#030 through \#060 due to Focus II recorder availability. Each of the four recorders also recorded GPS-based IRIG-B timecode on one channel for later consolidation of all the datasets.

The center of a $1000-\mathrm{ft}$ ( $304.8 \mathrm{~m}$ ) radius spiral microphone array provided and operated by the Boeing Company was positioned at the extended line of the linear array. The spiral microphone array data were gathered to investigate directionality of the sonic boom propagation below Mach cutoff threshold. ${ }^{90}$ Details of the spiral array are discussed in ref. 8 of this paper. This paper will focus exclusively on the data collected by the primary linear array. The data from the secondary spiral array will be investigated in the future.

All microphone locations were computed with geodesic software and located using a Javad (San Jose, California, USA) Triumph-VS carrier-phase differential GPS system to within about $1 \mathrm{inch}(2.5 \mathrm{~cm})$. At each microphone location a $2-\mathrm{ft}(0.6-\mathrm{m})$ by $2-\mathrm{ft}(0.6-\mathrm{m})$ by $3 / 4-\mathrm{inch}(2-\mathrm{cm})$ square of plywood was used as a ground board, with the primary microphone centered on the board; and the second microphone, for those seven locations with two microphones, half way between the center and the edge of the board (Fig. 5). Each board was covered with an adhesive vinyl cover commonly used to cover kitchen shelving to prevent warping from any dew or rain. A sheet metal template and environmentally safe water-based blue spray paint was used to mark each location on the dry lakebed with an " $X$ " that would define the location for the corners of the ground board. 


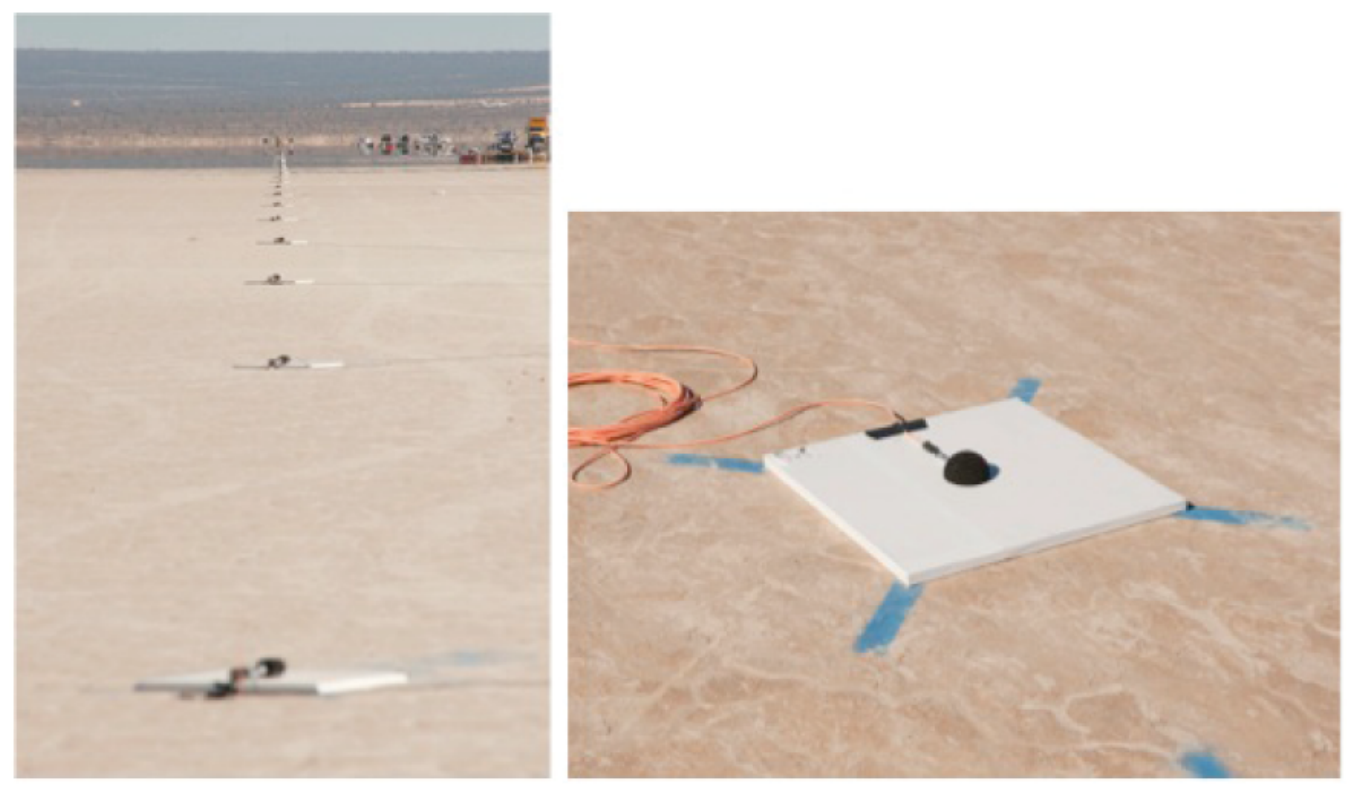

Figure 5. Microphones on ground boards.

\section{Meteorological Systems}

For pre-flight mission planning and post-flight sonic boom analysis, atmospheric sounding data were gathered using an airborne weather measurement package consisting of a Lockheed Martin (Bethesda, Maryland, USA) model LMS6 radiosonde unit. The unit was able to measure temperature, relative humidity, pressure, wind direction, and wind speed derived from GPS differential measurement at a ground station and the radiosonde. This package provided data from near-ground up to the flight altitudes of the airplane.

Ground-level meteorological measurements for post-flight sonic boom analysis were taken using solar-powered surface weather towers that measured temperature, relative humidity, wind direction, wind speed, and pressure at GPS time-synced $0.5 \mathrm{~s}$ increments. The pressure, temperature, and wind sensors were at heights of approximately $4 \mathrm{ft}$ $(1.2 \mathrm{~m}), 6 \mathrm{ft}(1.8 \mathrm{~m})$, and $10 \mathrm{ft}(3.0 \mathrm{~m})$ above the ground, respectively. Three weather towers were located $100 \mathrm{ft}$ $(30.5 \mathrm{~m})$ from microphones \#001, \#030, and \#060, perpendicular to the array line and on the southern side of the arrays.

\section{B. Aircraft}

Two aircraft were used during the FaINT flight campaign. This section will discuss the configurations of each.

\section{F-18 Airplane}

NASA Armstrong F-18B airplane, tail number 852 was used to generate the sonic booms for FaINT. Tail number 852 is a standard F-18B airplane, and was configured with a centerline fuel tank. Internally this airplane was equipped with a Research Quick Data System (RQDS) that converts the airplane 1553 bus data into pulse-code modulation data for telemetry and onboard recording. GPS-based IRIG-B timecode generator data were also recorded. The airplane was equipped with an Ashtech (Trimble Navigation, Ltd., Sunnyvale, California, USA) Z-12 GPS unit. The GPS data were post-processed after each flight to add in differential corrections from the AFRC base station.

Accurate placement of the sonic boom footprint on the microphone array required accurate knowledge of the Mach number and altitude of the airplane. The calibration of the airplane production air data system in the supersonic region has known errors on the order of $0.045 \mathrm{Mach}$, which can result in up to a $1.7 \mathrm{nmi}$ error in sonic boom location. ${ }^{10}$ For the range of Mach numbers flown during FaINT, this error has been shown to be approximately $+0.04 \mathrm{Mach},{ }^{11}$ and has been corrected appropriately in the data presented here.

\section{Airborne Acoustic Measurement Platform}

The TG-14 motorglider, tail number 149, (Fig. 6) was used to measure the sonic booms for FaINT above groundlevel turbulence. The TG-14 airplane is a NASA operated U.S. Air Force Test Pilot School airplane and is equipped with an acoustic sensor system. In this configuration the TG-14 airplane is called the Airborne Acoustic Measurement 
Platform (AAMP). Figure 6 shows the wingtip mounted B\&K model 4193 0.5-inch $(1.3 \mathrm{~cm})$ condenser microphone with a B\&K model UC0211 low frequency adapter, B\&K model UA0386 tapered nose cone, and B\&K model 2669C preamplifier. This assembly was connected to the instrumentation pallet in the cargo area shown in Fig.7. The microphone was amplified by a B\&K model 2690-A-OS2 Nexus ${ }^{\mathrm{TM}}$ amplifier, and then digitized by a LDS Dactron Focus II analog to digital converter. Cockpit audio was also digitized by the Focus II. LDS Dactron RT Pro software hosted on a Fujitsu (Tokyo, Japan) P1630 tablet PC computer was used to record the data. Instrumentation Technology Systems (Northridge, California, USA) model 6155D GPS-based IRIG-B timecode generator data were also recorded. An Ashtech Z-Xtreme carrier-phase differential GPS receiver measured the position and velocity of the TG-14 airplane. All these systems were battery powered.

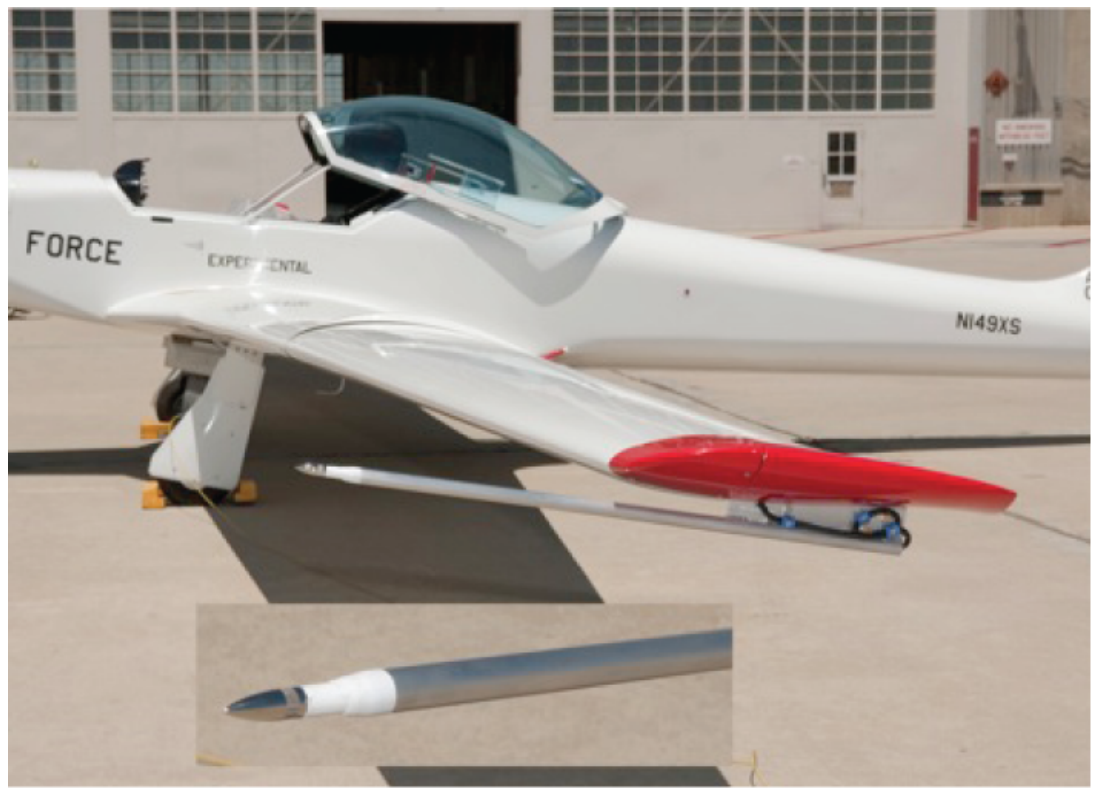

Figure 6. Wingtip mounted microphone on TG-14 airplane, tail number 149, with inset close up of microphone.

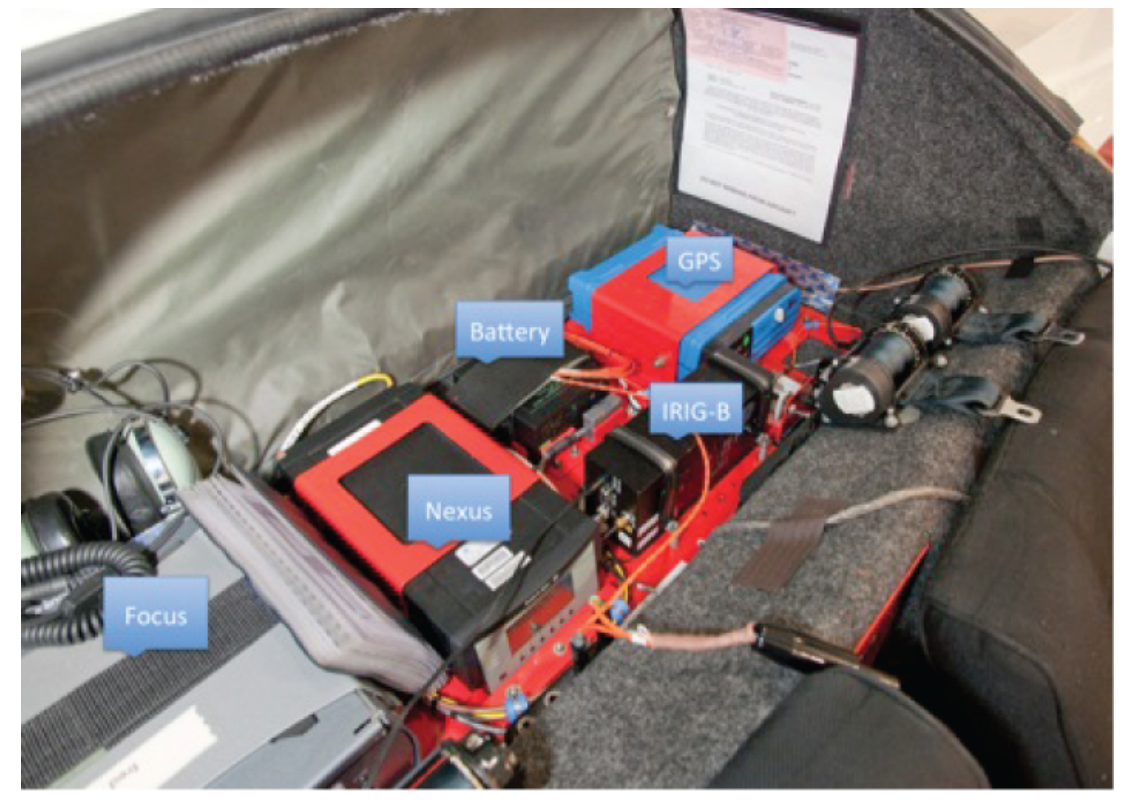

Figure 7. TG-14 instrumentation pallet. From left to right: Focus II recorder, Nexus amplifier, battery, GPSbase IRIG-B timecode generator, and Z-Xtreme GPS receiver. 
It was discovered during checkout flights that the microphone portion of the AAMP system would not record properly when the propeller of the TG-14 airplane was rotating. To address this problem, prior to recording sonic booms the TG-14 engine was turned off and the data were collected during gliding flight. The engine would be restarted to position the TG-14 airplane for the next supersonic pass of the F-18 airplane. A Garmin International, Inc. (Olathe, Kansas, USA) model GPSMAP 496 handheld GPS receiver aided positioning of the TG-14 airplane.

\section{Mission Planning and Cutoff Altitude Calculations}

The basic test setup for the Mach cutoff experiment was to fly the airplane straight and level for a period of time so as to generate a consistent Mach cutoff caustic directly above the microphone array. By doing so the entire microphone array would be exposed to the evanescent wave field in the shadow zone. Combinations of aircraft Mach number and flight altitude were chosen in an effort to produce a target range of $\mathrm{Z}_{\mathrm{CO}}$ between 2500- to 8000-ft (762.0to 2438.4-m) AGL.

For FaINT mission planning, a preflight GPS radiosonde weather balloon was launched to gather the atmospheric sounding. After a nominal initial flight altitude and heading was chosen, Eqs. (1) to (5) ${ }^{4}$ were used to compute a Mach number for a target $Z_{\mathrm{CO}}$ based on atmospheric conditions.

$\mathrm{M}_{\mathrm{CO}}$ conditions are derived from:

$$
\left(M_{T}-M\right) \geq 0 \rightarrow V_{P} / V_{G} \geq 1.0
$$

where the sonic boom ray propagation speed $\left(\mathrm{V}_{\mathrm{P}}\right)$ and airplane ground speed $\left(\mathrm{V}_{\mathrm{G}}\right)$ are:

$$
\begin{gathered}
V_{P}=\left\{a(Z)-u_{n}(Z)\right\} \\
V_{G}=M a_{0}-u_{n_{0}}
\end{gathered}
$$

For equations 2 and 3:

$$
u_{n}=u \cos (\psi-\eta)
$$

where,

$$
\begin{aligned}
& a: \text { speed of sound } \\
& n: \text { normal to wind direction } \\
& u: \text { horizontal wind speed } \\
& \psi: \text { airplane heading (true north) } \\
& \eta: \text { direction from which wind blows (true north) }
\end{aligned}
$$

The subscript " 0 " denotes atmospheric conditions, at airplane altitude.

Since $V_{P}$ increases as the sonic boom rays propagate downward from the airplane (Eq. (2)), the rays refract complete above ground at the maximum altitude in which $V_{P}$ equals the airplane ground speed (Eq. (3)). This altitude is $\mathrm{Z}_{\mathrm{CO}}$ :

$$
Z_{C O}=Z @ \max \left\{V_{P} \geq V_{G}\right\}
$$

Equation (3) was used to compute the flight Mach number that satisfies Eq. (5), for a given flight altitude, heading and target $\mathrm{Z}_{\mathrm{CO}}$.

After the initial flight altitude, heading, and Mach number were computed, these data were then run through PCBoom, ${ }^{12}$ a sonic boom propagation prediction computer package developed by Wyle. PCBoom does not give solutions below the cutoff altitude, so a theoretical sonic boom footprint was computed at altitude $\mathrm{Z}_{\mathrm{CO}}$. The airplane flight path was then shifted laterally to compensate for any crosswind affects predicted by PCBoom. Because it was only a lateral shift, the wind component $\left(\mathrm{u}_{\mathrm{n}}\right)$ in the above equations is unaltered.

During flight, ground personnel used audible cues to adjust the F-18 Mach number as necessary. After each pass, ground personnel along the microphone array would subjectively report the type of sonic boom sound heard using predefined visual signals. Based on this feedback the F-18 pilot could, if necessary, be instructed by way of radio communication link to decrease or increase the Mach number. For example, a distinct $\mathrm{N}$-wave heard across the array 
would require a decrease in Mach number. These adjustments were typically only on the order of Mach 0.02 to 0.04 at a time since $\mathrm{Z}_{\mathrm{CO}}$ is very sensitive to changes in airplane speed, as discussed later in Section III.E.

For each flight pass the TG-14 AAMP was planned to be flown at an altitude just below $\mathrm{Z}_{\text {Co. }}$. The intent was to collect sonic boom measurements near the Mach cutoff caustic to compare with ground measurements. The same PCBoom sonic boom propagation code was used to predict the time that the caustic would be directly above the microphone array. The AAMP was used to collect measurements below the caustic at that time.

\section{Test Point Matrix}

Mach cutoff tests for FaINT consisted of six flights over three days. Each flight used an F-18 airplane as the sonic boom source. There were $36 \mathrm{M}_{\mathrm{CO}}$ passes total, ranging from 34,400- to 39,300-ft (10485.1- to 11978.6-m) Hp and Mach 1.128 to 1.174 . Table 1 lists the mean flight conditions as flown by the F-18 airplane during each pass. It should be noted that these are average values.

Table 1. FaINT F-18 Mach cutoff test point matrix.

\begin{tabular}{|c|c|c|c|c|c|}
\hline Date & $\begin{array}{l}\text { Flight } \\
\text { number }\end{array}$ & Pass number & Mach & Altitude, $\mathrm{ft} \mathrm{Hp}$ & $\begin{array}{l}\text { Heading, degrees, } \\
\text { true }\end{array}$ \\
\hline \multirow{12}{*}{$\begin{array}{l}\text { November 5, } \\
2012\end{array}$} & \multirow{6}{*}{1} & 1 & 1.171 & 38,760 & 262 \\
\hline & & 2 & 1.162 & 39,190 & 259 \\
\hline & & 3 & 1.160 & 39,160 & 260 \\
\hline & & 4 & 1.168 & 39,250 & 261 \\
\hline & & 5 & 1.167 & 39,260 & 261 \\
\hline & & 6 & 1.174 & 38,930 & 261 \\
\hline & \multirow{6}{*}{2} & 1 & 1.154 & 39,080 & 259 \\
\hline & & 2 & 1.172 & 39,210 & 262 \\
\hline & & 3 & 1.165 & 39,030 & 262 \\
\hline & & 4 & 1.154 & 39,090 & 259 \\
\hline & & 5 & 1.157 & 39,080 & 260 \\
\hline & & 6 & 1.160 & 39,140 & 260 \\
\hline \multirow{13}{*}{$\begin{array}{l}\text { November 6, } \\
2012\end{array}$} & \multirow{6}{*}{3} & 1 & 1.152 & 36,060 & 259 \\
\hline & & 2 & 1.156 & 36,080 & 260 \\
\hline & & 3 & 1.164 & 36390 & 259 \\
\hline & & 4 & 1.154 & 36,230 & 260 \\
\hline & & 5 & 1.159 & 36,250 & 257 \\
\hline & & 6 & 1.159 & 36,190 & 257 \\
\hline & \multirow{7}{*}{4} & 1 & 1.128 & 34,410 & 257 \\
\hline & & 2 & 1.148 & 35,630 & 258 \\
\hline & & 3 & 1.132 & 36,450 & 259 \\
\hline & & 4 & 1.135 & 37,060 & 258 \\
\hline & & 5 & 1.160 & 36,290 & 258 \\
\hline & & 6 & 1.165 & 35,990 & 259 \\
\hline & & 7 & 1.133 & 35,350 & 259 \\
\hline \multirow{11}{*}{$\begin{array}{l}\text { November 7, } \\
2012\end{array}$} & \multirow{6}{*}{5} & 1 & 1.135 & 35,970 & 256 \\
\hline & & 2 & 1.141 & 36,150 & 258 \\
\hline & & 3 & 1.137 & 35,860 & 259 \\
\hline & & 4 & 1.142 & 36,000 & 260 \\
\hline & & 5 & 1.168 & 36,370 & 258 \\
\hline & & 6 & 1.164 & 35,490 & 261 \\
\hline & \multirow{5}{*}{6} & 1 & 1.140 & 39,250 & 259 \\
\hline & & 2 & 1.154 & 39,210 & 258 \\
\hline & & 3 & 1.149 & 39,220 & 259 \\
\hline & & 4 & 1.159 & 39,110 & 256 \\
\hline & & 5 & 1.167 & 39,230 & 257 \\
\hline
\end{tabular}

10

American Institute of Aeronautics and Astronautics 


\section{Analysis and Results}

Research emphases of this paper include an appropriate metric for describing sonic boom waveforms in the shadow zone; improvements on the calculation of Mach cutoff parameters using flight data; an empirical model for noise levels in the Mach cutoff shadow zone; and an analysis of the sensitivity of Mach cutoff flight conditions to small changes in atmospheric conditions.

\section{A. Appropriate Metrics for Mach Cutoff Acoustics}

Overpressure alone is not sufficient for all sonic boom analysis, because peak values do not offer insight into characteristics such as frequency content, rise time and signature length. Capturing these characteristics is essential to understanding sonic booms in the shadow zone. Metrics used by the sonic boom community, such as the $70 \mathrm{~ms}$ integrated ${ }^{13} \mathrm{PL}_{70}$, may be less applicable for the waveform shape of the evanescent waves in the shadow zones below $\mathrm{Z}_{\mathrm{CO}}$ and beyond lateral cutoff of a traditional sonic boom carpet. The acoustic signature in the shadow zone is highly variable in duration and impulsiveness and the short integration time of the $\mathrm{PL}_{70}$ metric is not well suited for these longer, duration-varying sounds.

As discussed in Ref. 8, an alternate acoustic metric may be more applicable for signatures of the type experienced in the Mach cutoff shadow zone. This metric uses Stevens' Mark VII PL method, with the input determined by Sound Exposure Level (SEL) $1 \mathrm{~s}$ normalized method of integration defined in ISO $1996 .{ }^{14}$ This metric is referred to as Perceived Sound Exposure Level (PLSEL). Reference 8 compared PLSEL with several commonly used sonic boom acoustic metrics, and determined it to be a more applicable metric for the type of waveforms in the shadow zone.

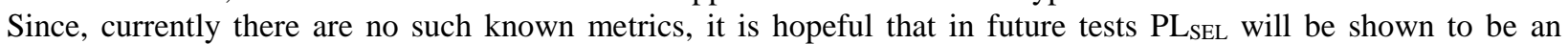
applicable human response metric for shadow zone acoustics. As a result, PLSEL was used to analyze sonic booms below $\mathrm{Z}_{\mathrm{CO}}$ in this paper.

\section{B. Mach Cutoff Calculations}

The method for determining $\mathrm{Z}_{\mathrm{CO}}$ in flight below $\mathrm{M}_{\mathrm{T}}$ was discussed in Section II.C, but there is no direct mathematical relationship between cutoff altitude and the $\mathrm{M}_{\mathrm{T}}$ of an airplane (Eq. (6)): ${ }^{4}$

$$
M_{T}=\frac{1}{a_{0}}\left[V_{P_{\max }}+u_{n_{0}}\right]
$$

$\mathrm{V}_{\mathrm{Pmax}}$ is the maximum ray propagation speed $\left(\mathrm{V}_{\mathrm{P}}\right.$, Eq. (2)) that occurs between the airplane and the ground. Generally, this maximum occurs at the ground, but can occur well above the ground due mostly to temperature inversions. A majority of the FaINT flights were conducted early in the morning when temperature inversions are most likely, resulting in $V_{P \max }$ occurring above the ground. Figure 8 shows an example of flight and weather conditions where $\mathrm{V}_{\mathrm{Pmax}}$ was not on the ground.

For a given flight altitude $\mathrm{Z}_{\mathrm{CO}}$ is a function of both atmospheric conditions and airplane Mach number, while $\mathrm{M}_{\mathrm{T}}$ is dependent only on atmospheric conditions for a given flight altitude. Therefore, there is no benefit in associating

the abstract $\mathrm{M}_{\mathrm{T}}$ to noise levels in the shadow zone. That is why the parameter $\left(\mathrm{M}_{\mathrm{T}}-\mathrm{M}\right)$ is useful. It is related to $\mathrm{Z}_{\mathrm{CO}}$ (Eqs. (3) and (4)), and monitoring flight conditions in terms of Mach number is more intrinsic to conventional airplane piloting operations than doing so in terms of $\mathrm{Z}_{\mathrm{CO}}$. 


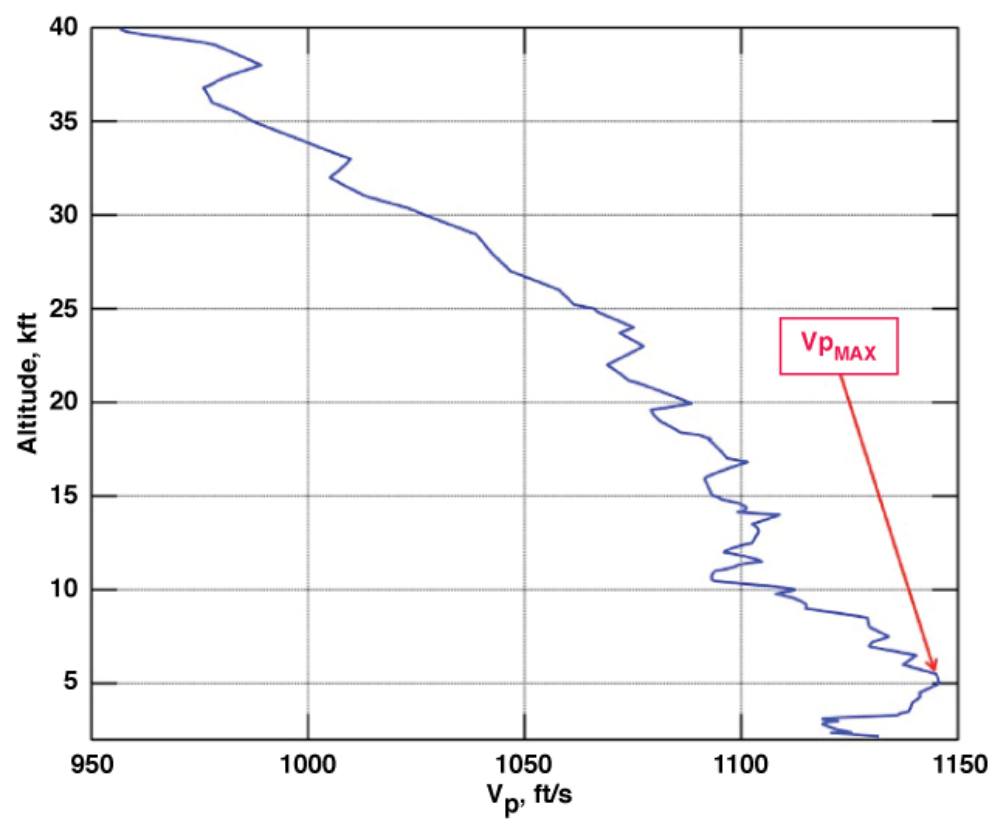

Figure 8. Example of $V_{P}$ inversion.

Figure 9 shows the PLSEL profile for one FaINT flight pass. The left vertical axis corresponds to the circle symbols (o), and shows the PLSEL as measured by the ground microphone array. Each symbol is a separate microphone measurement. The right vertical axis corresponds to the cross symbols $(+)$ and shows the difference between the actual Mach number of the airplane and theoretical $\mathrm{M}_{\mathrm{T}}$, and the horizontal axis is the time in seconds after the first microphone recording. The data have been aligned such that the sonic booms that were measured (left axis) were generated when the airplane was at the corresponding flight conditions (right axis). For example, in Fig. 9 the PLSEL data begin at 55,430.5 s after midnight, but the $\left(\mathrm{M}_{\mathrm{T}}-\mathrm{M}\right)$ data started at 55,314.0 s. That means it took approximately $116.5 \mathrm{~s}$ for the sonic booms to reach the microphones from the airplane. PCBoom ${ }^{12}$ was used to estimate the time the sonic boom was generated, by predicting a sonic boom footprint at the calculated $\mathrm{Z}_{\mathrm{CO}}$.

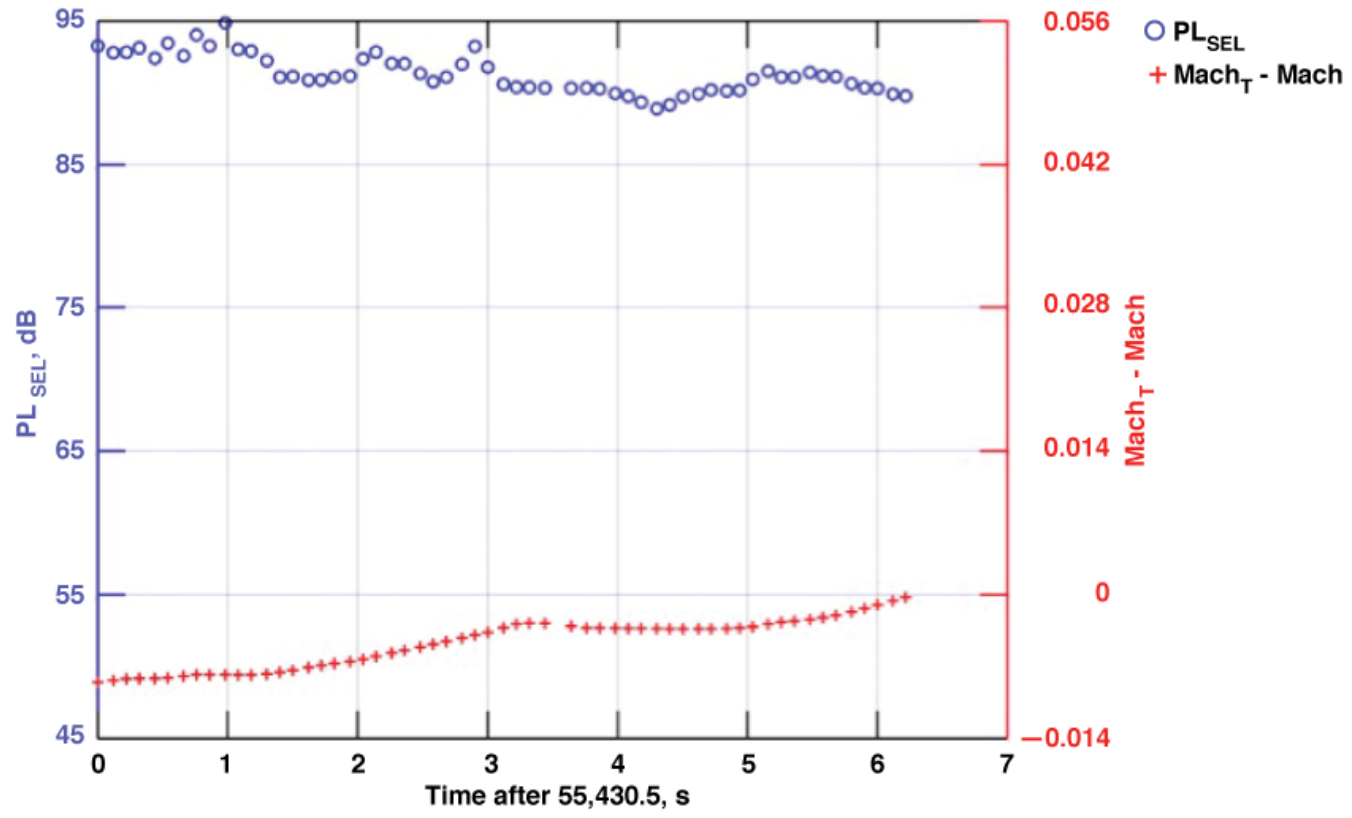

Figure 9. $\mathrm{M}_{\mathrm{T}}$ profile (flight 1, pass 1, generated at 55,314.0 s).

12

American Institute of Aeronautics and Astronautics 
For the case shown in Fig. 9, ( $\mathrm{M}_{\mathrm{T}}-\mathrm{M}$ ) is negative, meaning that that there is no Mach cutoff condition (Eq. (1)), and the sonic boom hit the ground. Consequently, the PLSEL levels are very high. Appendix A shows the average PLSEL and $\left(\mathrm{M}_{\mathrm{T}}-\mathrm{M}\right)$ for each flight pass. Appendix A is a summary of the FaINT Mach cutoff dataset.

Figures 10 and 11 show PL $L_{S E L}$ profiles for cases of increasing $\left(\mathrm{M}_{\mathrm{T}}-\mathrm{M}\right)$. As expected, $\mathrm{PL}_{\mathrm{SEL}}$ is generally lower for higher values of $\left(\mathrm{M}_{\mathrm{T}}-\mathrm{M}\right)$. As will be discussed in the following section, Section III.C, $\mathrm{Z}_{\mathrm{CO}}$ also affects $\mathrm{PL}_{\mathrm{SEL}}$.

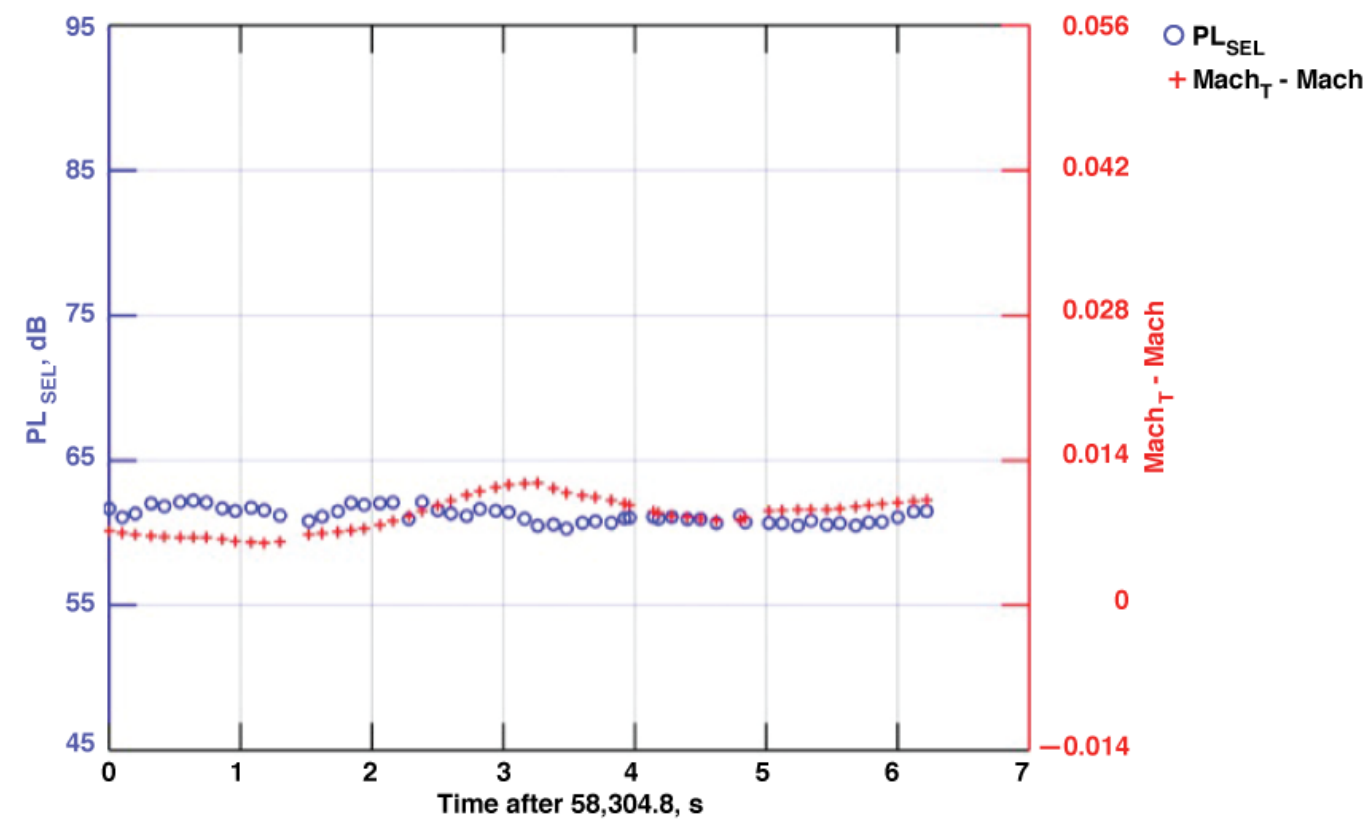

Figure 10. MT profile (flight 3, pass 6, generated at 58,205.0 s).

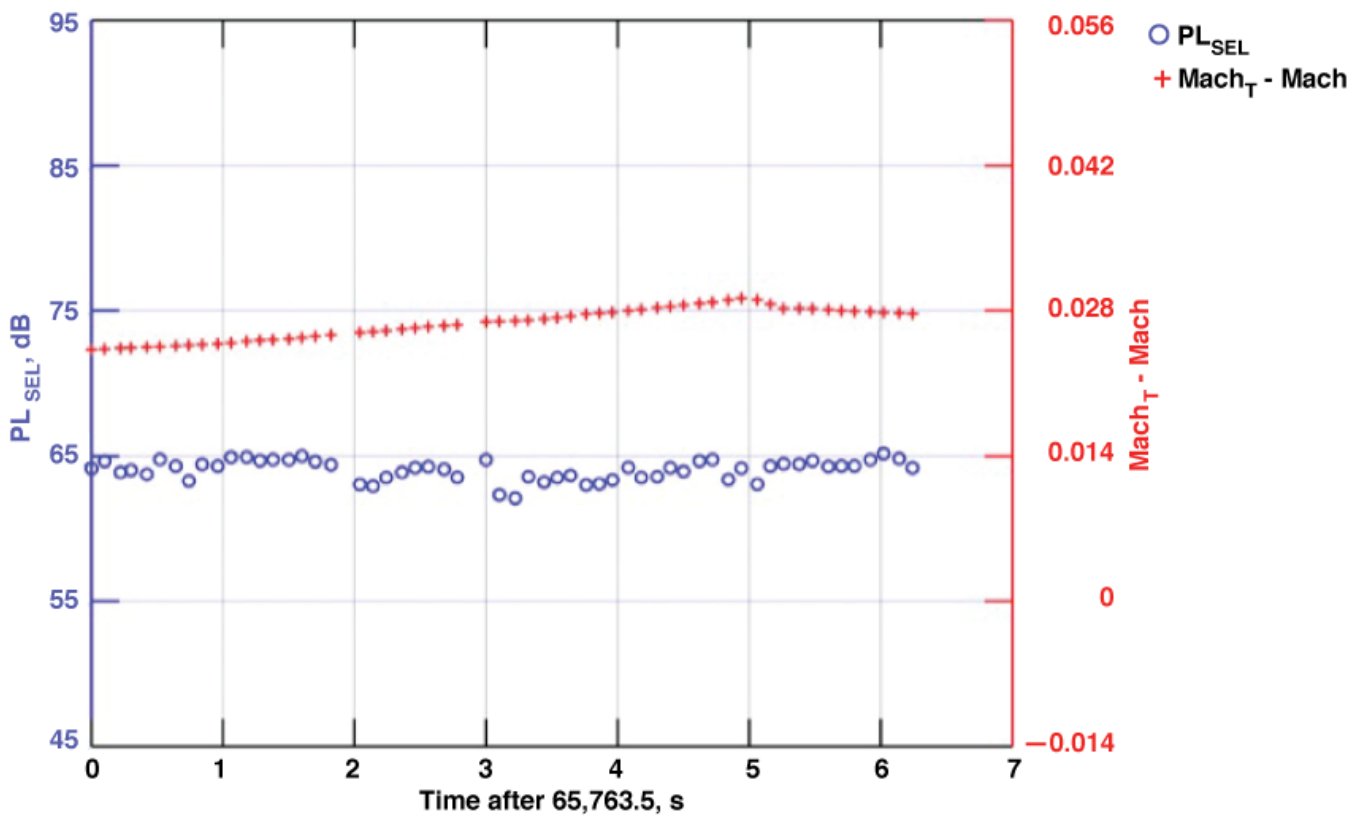

Figure 11. $M_{\mathrm{T}}$ profile (flight 2, pass 1, generated at 65,656.8 $\mathrm{s}$ ).

This analysis confirms the ability to accurately compute $\left(\mathrm{M}_{\mathrm{T}}-\mathrm{M}\right)$ and is the first step in relating it to the noise levels in the shadow zone. It also demonstrates the challenging ability to correlate shadow zone measurements on the ground with the time they were generated by the airplane. Such results are not known to have been published before. This consideration is important because flight conditions during real world tests are never actually constant, and can 
sometimes be very unsteady. Figure 12 shows the variation in Mach number as flown for the entire pass 6 of flight 3 . The red portion of the data are the estimated time during which the airplane generated the sonic booms measured by the microphone array, shown in Fig. 10. Because of the unsteadiness in flight conditions it is imperative to be able to match sonic boom measurements on the ground with the airplane flight conditions when it generated the sonic booms, particularly for the data presented in the following section, Section III.C. This concept might have been overlooked or overly simplified in previous Mach cutoff studies.

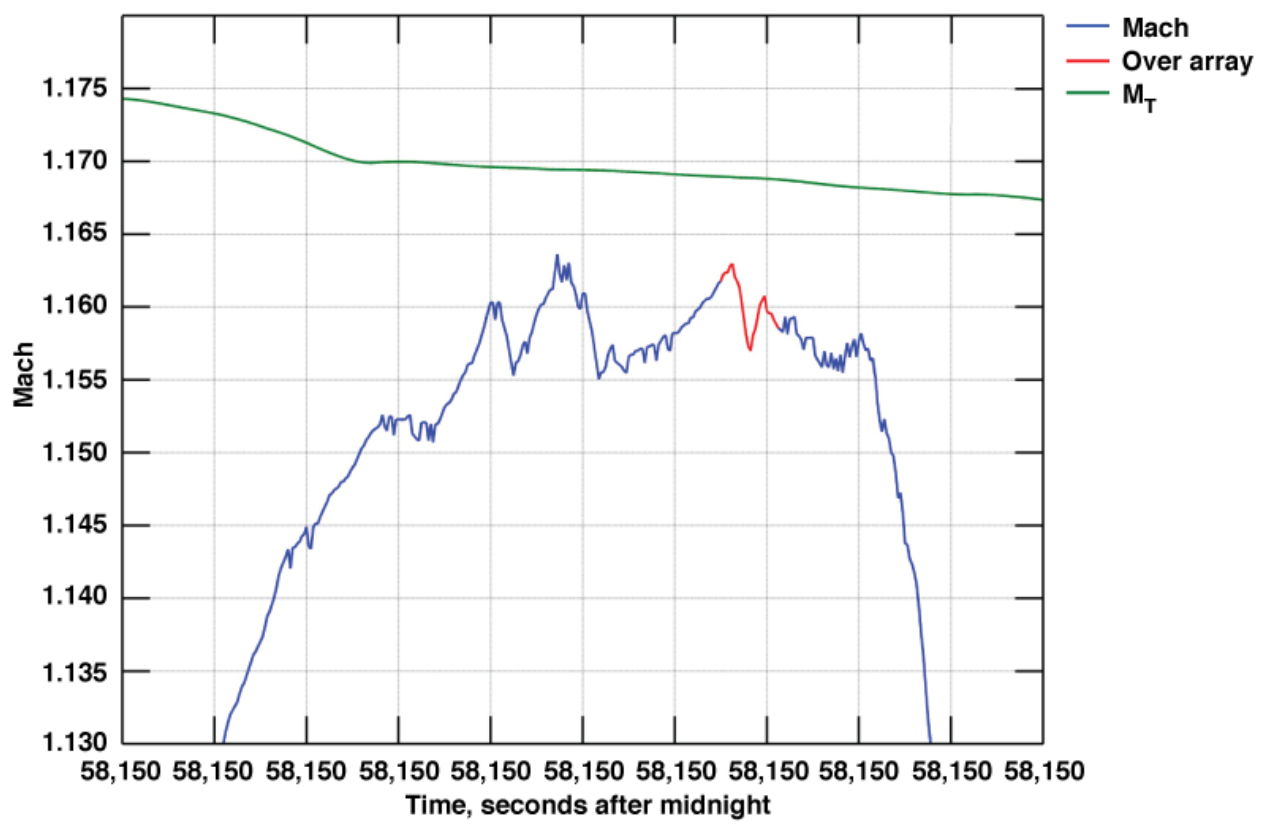

Figure 12. Mach number as flown (flight 3, pass 6).

\section{Metrics Versus Mach Cutoff}

An analytical relationship between $\mathrm{M}_{\mathrm{CO}}$ conditions and PLSEL is a vital step in commercial supersonic transportation using the boomless model. While there are tools to estimate primary sonic boom carpet acoustic metrics, there are currently no such tools for the shadow zone that could be realistically implemented into any serviceable flight planning method. While Figs. 10 and 11, show a relationship between flight speeds below $\mathrm{M}_{\mathrm{T}}$ and PLsEL, there is an additional component that must be considered. As shown in Fig. 13 different $\left(\mathrm{M}_{\mathrm{T}}-\mathrm{M}\right)$ can easily result in different sound levels on the ground. Similarly, different $Z_{\mathrm{CO}}$ can result in different sound levels on the ground, as illustrated in Fig. 14. 


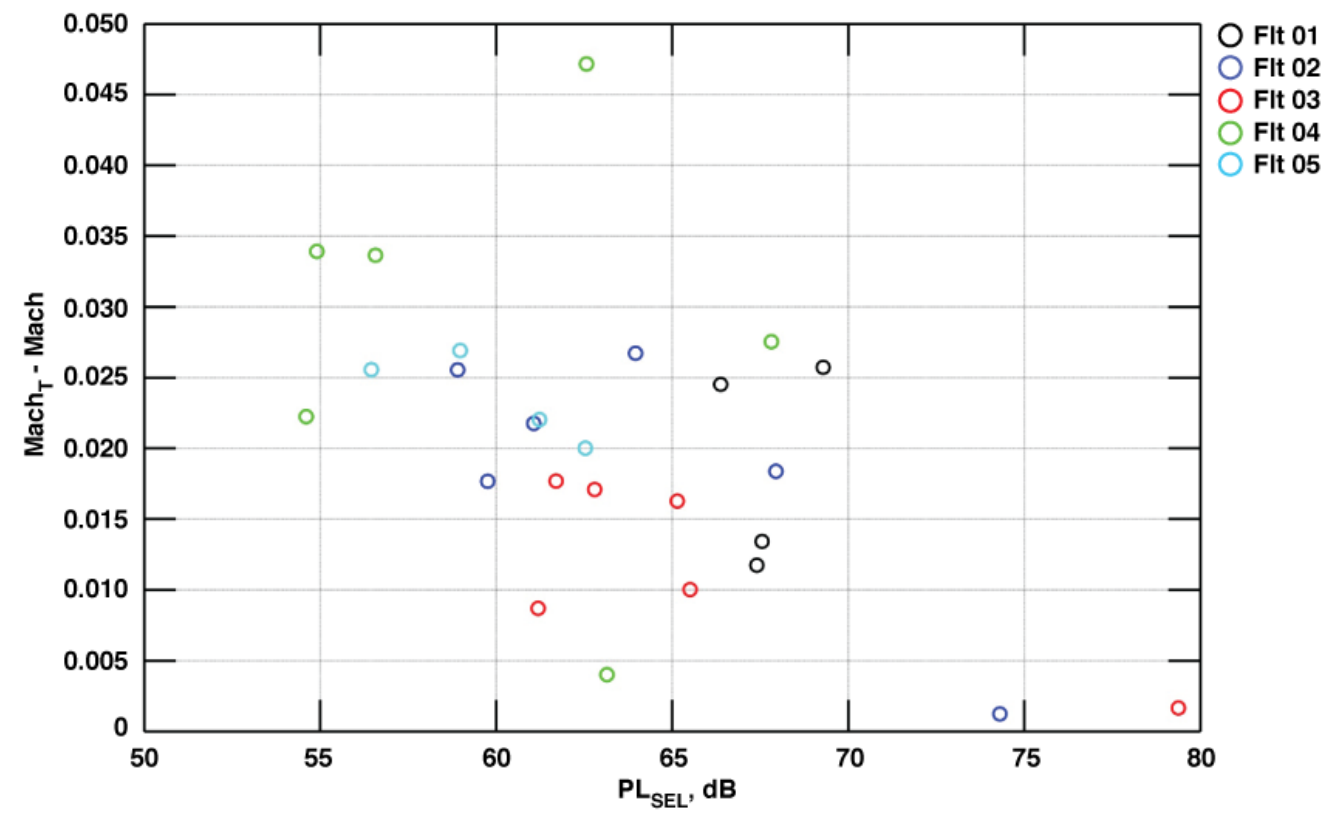

Figure 13. Relationship between human sound exposure level metric and Mach threshold.

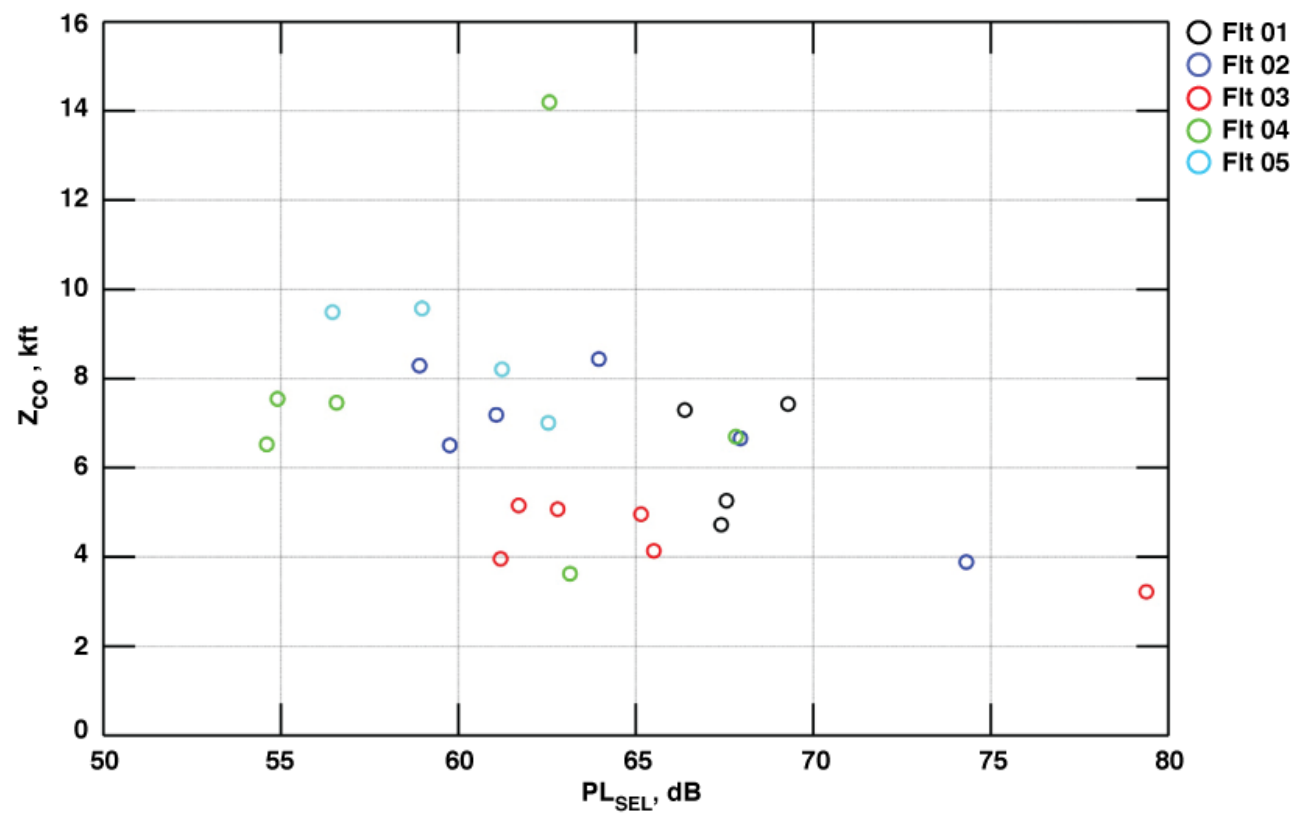

Figure 14. Relationship between human sound exposure level metric and Mach cutoff altitude.

Neither $\left(\mathrm{M}_{\mathrm{T}}-\mathrm{M}\right)$ or $\mathrm{Z}_{\mathrm{CO}}$ alone are adequate in estimated sound levels on the ground, because two flight conditions with the same $\left(\mathrm{M}_{\mathrm{T}}-\mathrm{M}\right)$, but different $\mathrm{Z}_{\mathrm{CO}}$ would most likely produce different PL $\mathrm{L}_{\mathrm{SEL}}$ since a higher $\mathrm{Z}_{\mathrm{CO}}$ means more attenuation in the shadow zone. So, it might be useful to "normalize" by $Z_{\mathrm{CO}}$. Figure 15 shows the results of the experiment represented by the relationship between $\left(\mathrm{M}_{\mathrm{T}}-\mathrm{M}\right)$, PLSEL, and $\mathrm{Z}_{\mathrm{CO}}$. Note that flight 6 was excluded from all results in Figs. 13 to 15. Flight 6 was performed during conditions of high wind, making the microphone data problematic to analyze. 


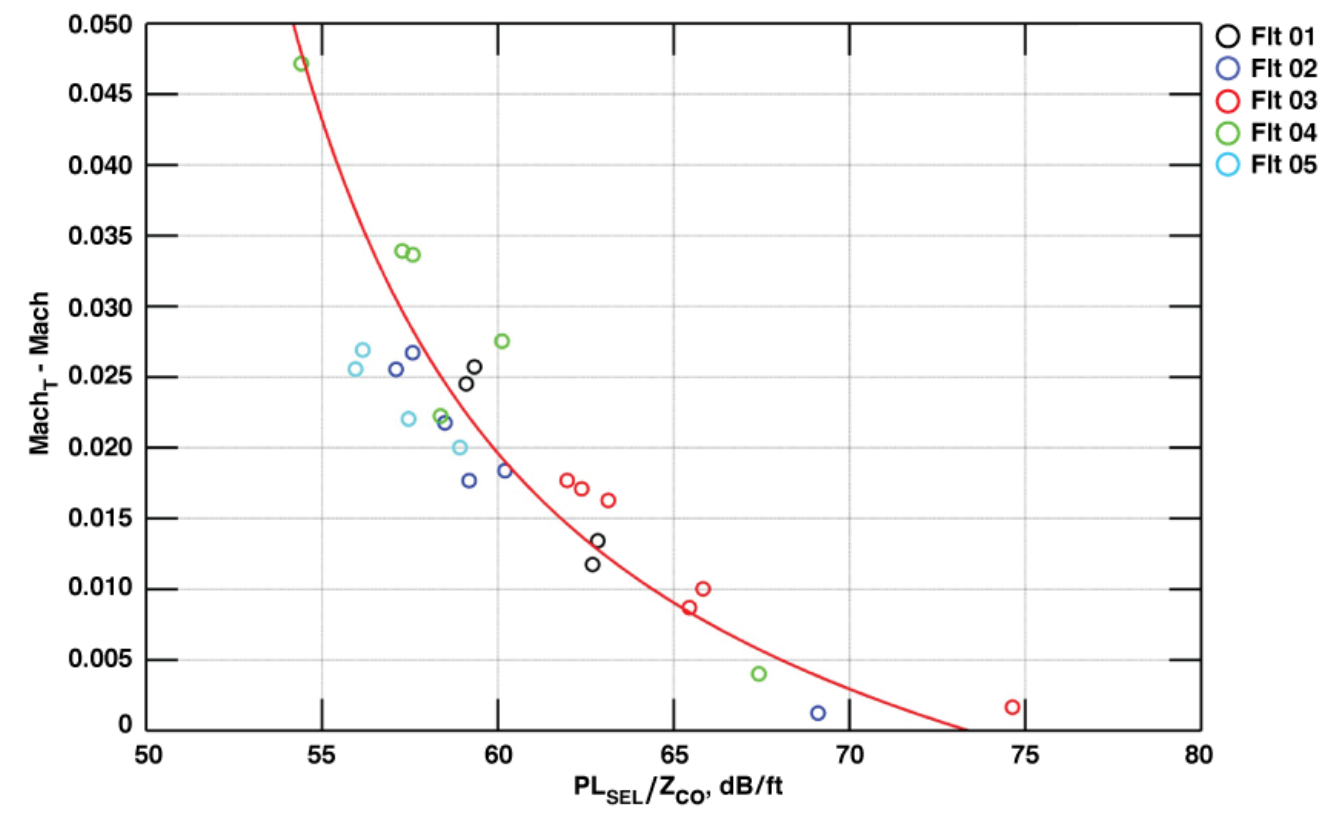

Figure 15. Relationship between a human sound exposure level metric and Mach cutoff flight conditions.

The vertical axis is as-flown $\left(\mathrm{M}_{\mathrm{T}}-\mathrm{M}\right)$, while the horizontal axis shows measured PLSEL normalized by as-flown $\mathrm{Z}_{\mathrm{CO}}$ (to account for the aforementioned attenuation distance), shown by the red exponentially decaying fit line. The result is a function with the structure shown in Eq. (7):

$$
P L_{S E L}=f\left(M_{T}-M, Z_{C O}\right)
$$

As expected the data reach an asymptote, and the function loses relevance when the airplane exceeds $\mathrm{M}_{\mathrm{T}}$, that is $\left(\mathrm{M}_{\mathrm{T}}\right.$ $-\mathrm{M}) \leq 0$, because $Z_{\mathrm{CO}}$ should be nonexistent. An exponential fit with $95 \%$ confidence bounds was performed for cases of $\left(\mathrm{M}_{\mathrm{T}}-\mathrm{M}\right)>0$, indicated by the red line in Fig. 15. Equations (8) and (9) show this function:

$$
P L_{S E L}=Z_{C O}\left[0.008923 e^{-104.4 \delta}+0.01447 e^{-25.05 \delta}\right]
$$

where,

$$
\delta=M_{T}-M
$$

Equation (8) is the first known empirical model for Mach cutoff shadow zone acoustics and is the first to allow the prediction of a sound exposure level metric for an airplane flying below $\mathrm{M}_{\mathrm{T}}$. Equation (8) also emphasizes the sensitivity of $\mathrm{PL}_{\mathrm{SEL}}$ to $\mathrm{M}_{\mathrm{T}}$ and $\mathrm{Z}_{\mathrm{CO}}$. As an example, using Eq. (8) with a $\mathrm{Z}_{\mathrm{CO}}$ of $6000 \mathrm{ft}(1828.8 \mathrm{~m})$, a change in $\left(\mathrm{M}_{\mathrm{T}}-\right.$ M) of 0.015 to 0.010 will result in PLsEL from $71 \mathrm{~dB}$ to $86 \mathrm{~dB}$ respectively.

\section{Safe Altitude Validation}

Haglund ${ }^{15}$ proposed the idea of a safe cutoff altitude $\left(Z_{S}\right)$ during the BREN tower study. $Z_{S}$ was defined to be "the lowest altitude reached by the shock wave." Additionally, the study suggested that there exists a buffer zone between $Z_{S}$ and the ground, required to attenuate the sonic boom to a "relatively small intensity." The depth of the buffer zone was given as Eq. $(10)^{15}$ :

$$
\Delta Z_{S}=(R)^{1 / 3}(L)^{2 / 3}
$$

where $L$ is the signal length, dependent on the airplane size, and $R$ is the radius of relative curvature of the caustic relative to the ray. $\mathrm{R}$ is a function of atmospheric conditions as shown in Eq. (11) ${ }^{15}$ : 


$$
R=\frac{-a}{\partial V_{P} / \partial Z}
$$

where $a$ is the speed of sound and $\mathrm{V}_{\mathrm{P}}$ was defined in equation 2 .

Haglund ${ }^{15}$ goes on to define the safe cutoff altitude $\left(Z_{S}\right)$ as Eq. (12):

$$
Z_{S}=Z\left(V_{P_{\max }}\right)+\Delta Z_{S}
$$

Physically, $\mathrm{Z}\left(\mathrm{V}_{\mathrm{P}_{\max }}\right)$ is the lowest possible altitude $\mathrm{Z}_{\mathrm{CO}}$ can be for the given atmospheric conditions. $\mathrm{Z}\left(\mathrm{V}_{\mathrm{P}_{\max }}\right)$ is independent of airplane Mach number. To validate the safe cutoff altitude theory Haglund ${ }^{15}$ relates $Z_{S}$ to actually flown $\mathrm{Z}_{\mathrm{CO}}$ with the measured fraction shown in Eq. (13):

$$
\text { Ratio }_{Z_{S}}=\left(Z_{C O}-Z_{S}\right) / \Delta Z_{S}
$$

While Haglund ${ }^{15}$ does not define the term "relatively small intensity," the results of the study show that Ratio ${ }_{Z_{\mathrm{S}}}$ values $>1.0$ had $\Delta \mathrm{P}$ of 0.0 to $0.08 \mathrm{psf}\left(0.0\right.$ to $3.8 \mathrm{~Pa}$ ), and Ratio $\mathrm{Z}_{\mathrm{S}}$ values between 0.0 and 1.0 had $\Delta \mathrm{P} 0.04$ to $0.21 \mathrm{psf}$ (1.9 to $10.1 \mathrm{~Pa}$ ). Table 2 shows a summary of the results from FaINT, in the form presented by Haglund. ${ }^{15}$ The detailed results can be found in Appendix A, Table 3.

Table 2. FaINT safe cutoff altitude results.

\begin{tabular}{|l|c|c|c|c|}
\hline \hline \multirow{2}{*}{ Cutoff location } & \multirow{2}{*}{ Ratio $_{\mathbf{Z}_{\mathbf{S}}}$} & \multirow{2}{*}{$\begin{array}{c}\text { FaINT } \\
\text { range of } \\
\text { PLSEL, dB }\end{array}$} & \multicolumn{2}{|c|}{ Range of $\Delta \mathbf{P}, \mathbf{p s f}$} \\
\cline { 4 - 5 } & & & FaINT & Haglund $^{15}$ \\
\hline Cutoff well above safe altitude & $>1.0$ & 55 to 69 & 0.01 to 0.10 & 0.00 to 0.08 \\
\hline Cutoff between one and two $\Delta Z_{\text {s }}$ above ground & 0.0 to 1.0 & 59 to 68 & 0.03 to 0.09 & 0.04 to 0.21 \\
\hline Cutoff below safe altitude but above ground & -0.8 to 0.0 & 60 to 79 & 0.03 to 0.33 & 0.10 to 0.35 \\
\hline
\end{tabular}

The FaINT data adds quantitative value to Haglund's ${ }^{15}$ safe altitude concept. The data suggest that $\mathrm{Ratio}_{\mathrm{Z}_{\mathrm{S}}}$ values $>0.0$ (a $\mathrm{Z}_{\mathrm{CO}}$ of at least one $\Delta \mathrm{Z}_{\mathrm{S}}$ above ground) is expected to produce PLSEL levels below $69 \mathrm{~dB}$.

\section{E. Sensitivity Analysis}

Because Mach cutoff is so heavily dependent on the atmosphere, it is prudent to do an atmospheric condition sensitively analysis. The focus of such an analysis is to determine how perturbations in atmospheric conditions would affect the noise level on the ground. To perform the sensitivity analysis nominal flight conditions were selected based on FaINT flight 4, pass 4 . This pass was chosen because it produced relatively high $\mathrm{Z}_{\mathrm{CO}}$ and low PLSEL (7500 ft $(2286.0 \mathrm{~m})$ and $57 \mathrm{~dB}$ respectively).

A Monte Carlo simulation was performed for the sensitivity analysis. The airplane flight conditions were held constant at Mach 1.135, 37,000-ft (11277.6-m) MSL, at 258-degrees true course. The atmospheric wind speed, wind direction, and temperature profiles were offset by randomly generated numbers from a normal distribution. The standard deviation of the random numbers were 3 knots, 10-degrees, and 3-degrees Celsius, respectively. The standard deviations were chosen because they were estimated to represent even the smallest, reasonable changes in atmospheric conditions over time and/or space. Predicted PLSEL values were computed using Eq. (8). The simulation was run until it produced 5000 Mach cutoff cases. All cases that did not result in Mach cutoff were excluded. Figure 16 shows the distribution of atmospheric conditions, while Fig. 17 shows the results. The red bars in Fig. 17 indicate the initial asflown results (Appendix A, Table 3). 

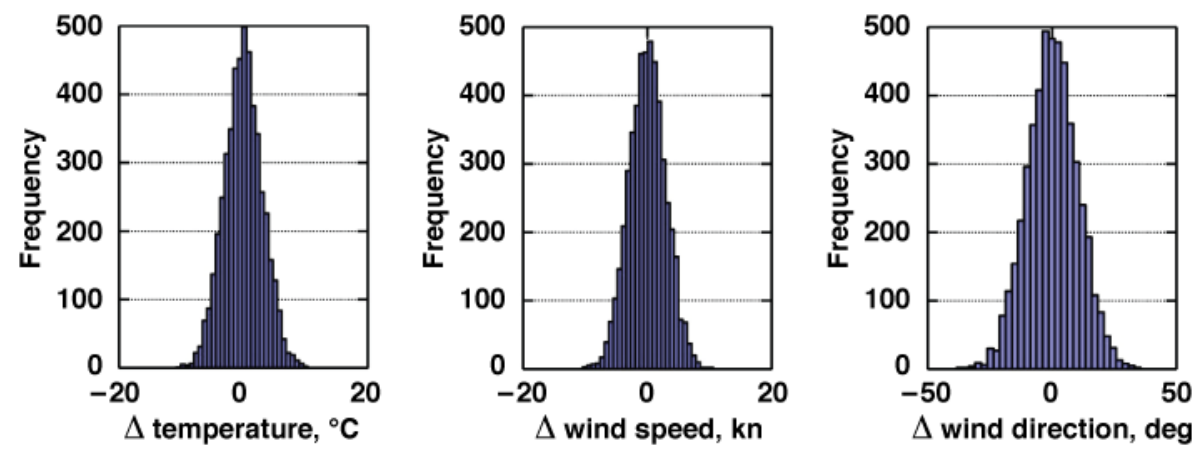

Figure 16. Mach cutoff sensitivity analysis perturbations; consistent flight conditions; 5000 case Monte Carlo simulation.
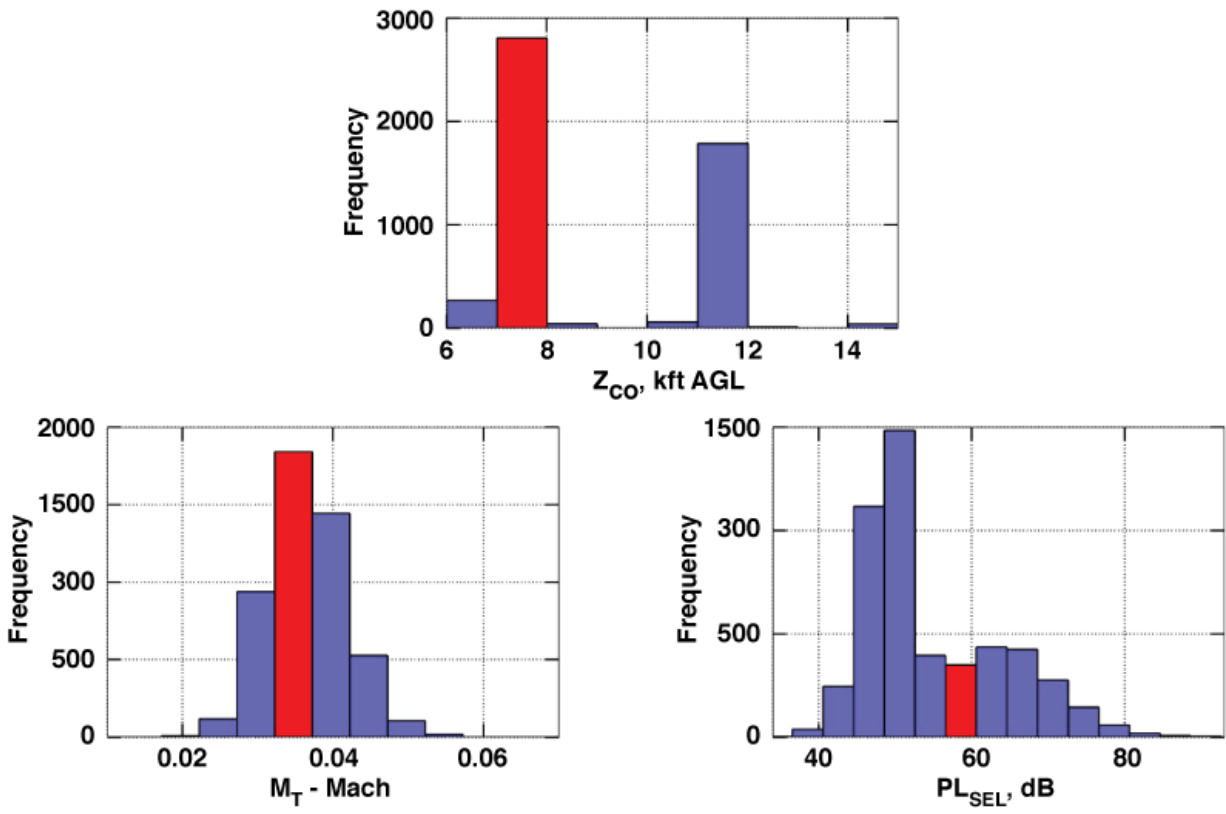

Figure 17. Mach cutoff sensitivity results; consistent flight conditions; 5000 case Monte Carlo simulation.

The results show the wide dispersion of noise levels due to relatively small changes in atmospheric conditions. While a majority of the data are below $60 \mathrm{~dB}$ and would most likely be considered quiet, some cases resulted in PLSEL greater than $80 \mathrm{~dB}$. Normal, non-cutoff sonic booms have been shown to produce PLSEL of that magnitude (Appendix A, Table 3).

Figure 17 shows distinctive bands/gaps in $\mathrm{Z}_{\mathrm{CO}}$ results. There is a range between about $8000 \mathrm{ft}(2438.4 \mathrm{~m})$ and $12,000 \mathrm{ft}(3657.6 \mathrm{~m})$ where there are very few solutions. The reason for the bands/gaps is due to above ground inversions in $V_{P}$. Figure 8 was used to discuss inversions that would result in $V_{P \max }$ being above the ground. Similar inversions can cause distinct bands of altitudes in which $\mathrm{Z}_{\mathrm{CO}}$ is unable to occur. The bands exist because, starting from the airplane altitude, $Z_{\mathrm{CO}}$ occurs at the first altitude where $V_{\mathrm{P}} \geq \mathrm{V}_{\mathrm{G}}$ (Eq. (5)). So only increasing maximum values of $V_{P}$ make up what can be referred to as the "effective $V_{P}$." Figure 18 shows the $V_{P}$ profile along with the effective $V_{P}$ for flight 4, pass 4; the nominal flight conditions for the Monte Carlo simulation. As an example, Fig. 18 illustrates that $\mathrm{Z}_{\mathrm{CO}}$ is possible at about 12,000-ft (3657.6-m) AGL, yet cannot occur again until around 8000-ft (2438.4 m) AGL. The inversion accounts for the similar gaps in $\mathrm{Z}_{\mathrm{CO}}$, shown in Fig. 17. 


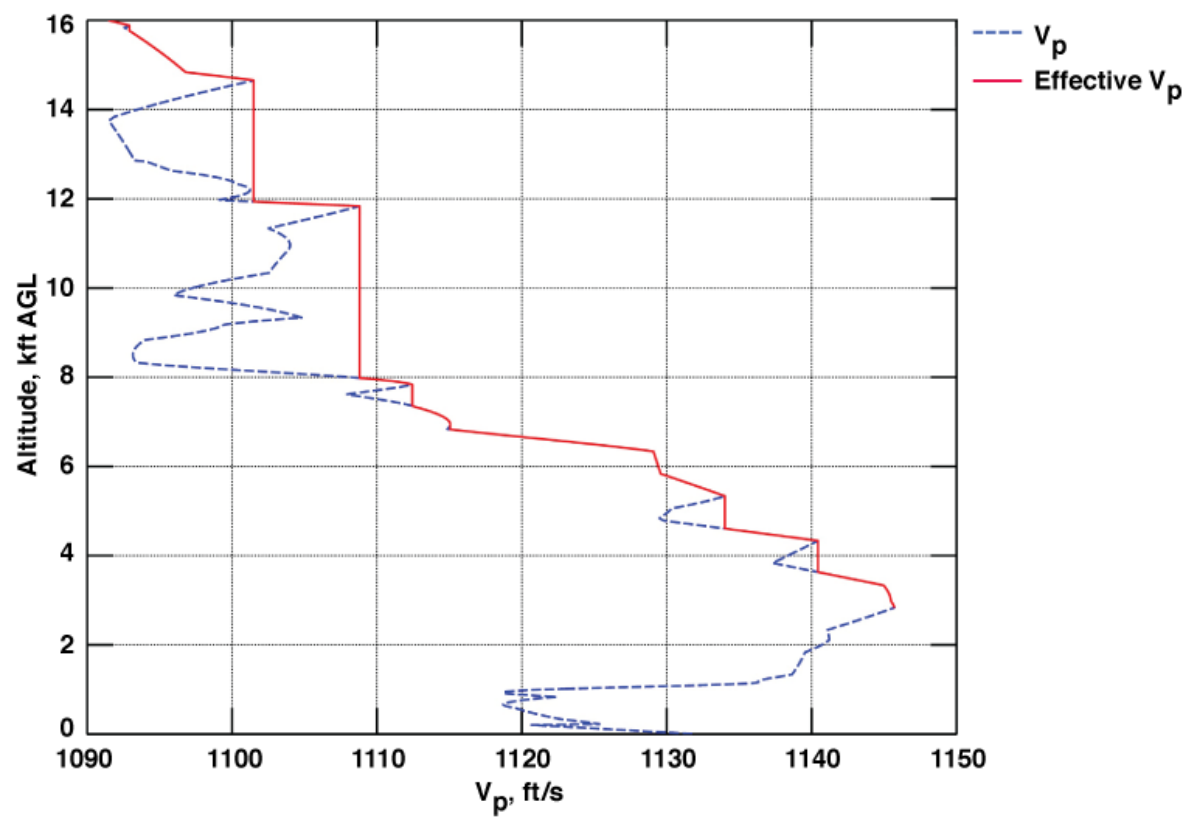

Figure 18. Effective $V_{P}$ (flight 4, pass 4).

In Section III.B, the importance of knowing precise flight conditions of an airplane was emphasized, because in real-world conditions there will be natural perturbations in speed, altitude, and heading (Fig. 12). Figures 19 and 20 show the inputs and results from a 5000 case simulation, with changes in both flight and atmospheric conditions. Nominal flight conditions were again selected based on FaINT flight 4, pass 4. The red bars in Fig. 20 indicate the initial as-flown results (Appendix A, Table 3).
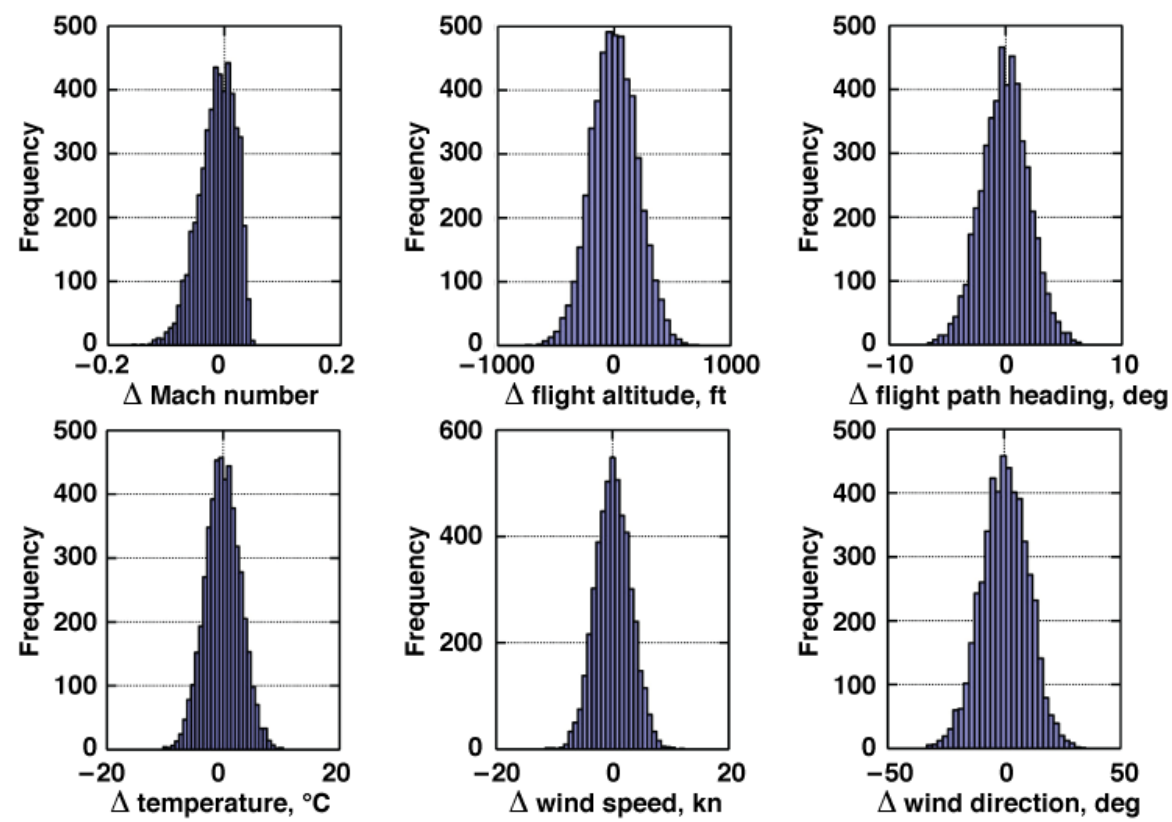

Figure 19. Mach cutoff sensitivity analysis perturbations; 5000 case Monte Carlo simulation. 

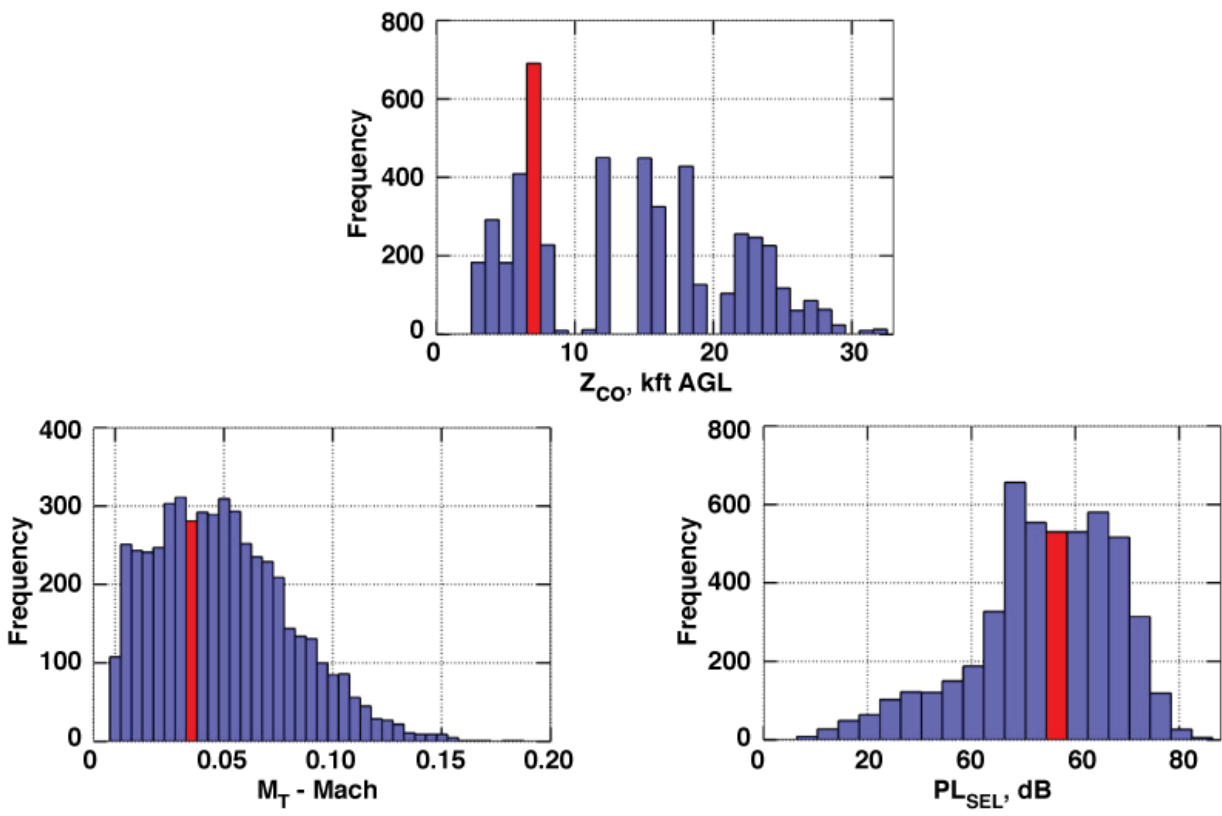

Figure 20. Mach cutoff sensitivity analysis results; 5000 case Monte Carlo simulation.

The dispersion in PLSEL increases significantly with aircraft perturbations, meaning more conservative flight planning for airplanes expecting to fly below $\mathrm{M}_{\mathrm{T}}$ as a method to reduce sonic boom noise. Airplane speed and altitude will have to be controlled, and real-time atmospheric conditions will have to be monitored, each to great accuracy.

\section{F. Midfield Measurements}

FaINT used the TG-14 AAMP to collect a database of Mach cutoff shadow zone acoustics in the midfield (far enough from the airplane that the shock structure is mostly constant, but above the atmospheric boundary layer). The ground microphone array recorded evanescent waves on the ground, while the AAMP attempted to record them just below $\mathrm{Z}_{\mathrm{CO}}$ and above the atmospheric boundary layer. The database is the first known of its kind and will provide a working reference as shadow zone acoustic numerical solutions such as LNTE$^{6}$ are developed and validated. The dataset might also be useful in further validating Eq. (8), if it is assumed that the AAMP recordings are at ground level.

In this paper a selection of the data from the AAMP will be presented to illustrate the validity of the databases and the accuracy of the system in measuring shadow zone acoustics. Figures 21 and 22 show comparisons between AAMP measurements (top) and a ground measurement (bottom). The red boxes are to emphasize the similar sonic boom pressure signature characteristics captured by each measurement. It should be noted that the AAMP measurements are free-field, while the ground measurements are subject to ground reflection. The AAMP measurements have a lower signal-to-noise ratio than the ground measurements, most likely due to the microphone being exposed to the freestream air during flight. 

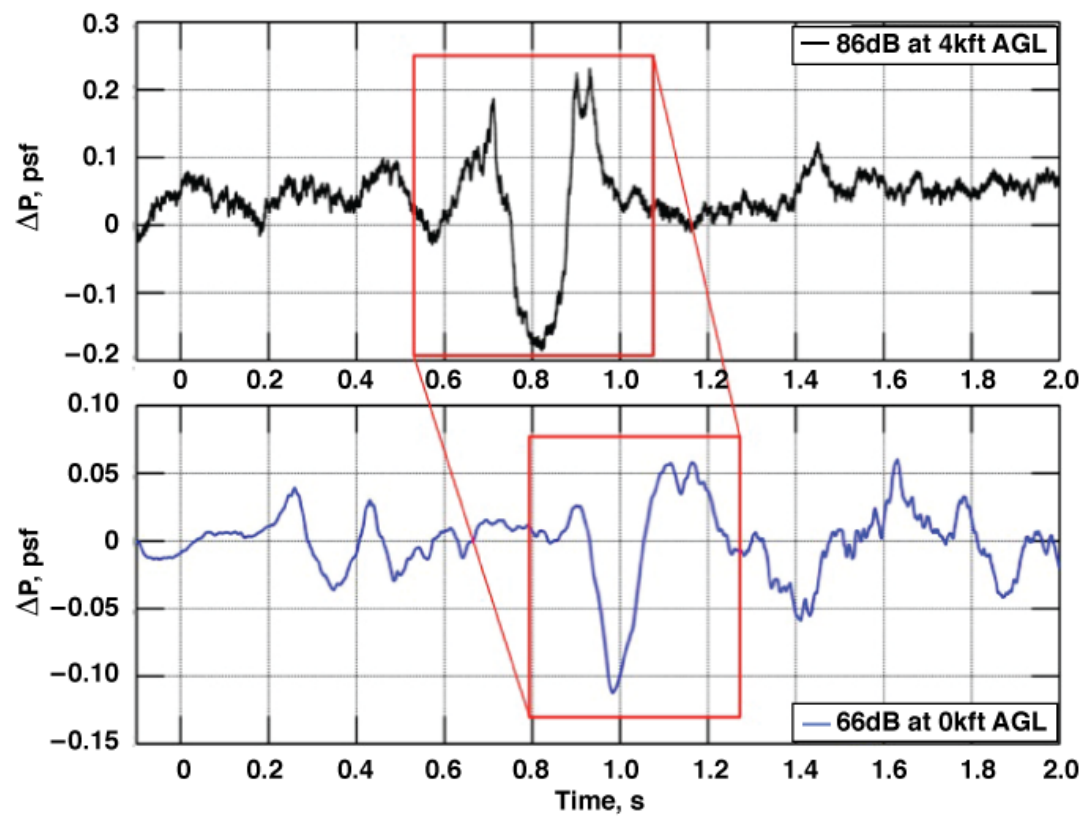

Figure 21. Comparison between midfield and ground level shadow zone measurements (flight 1, pass 3).
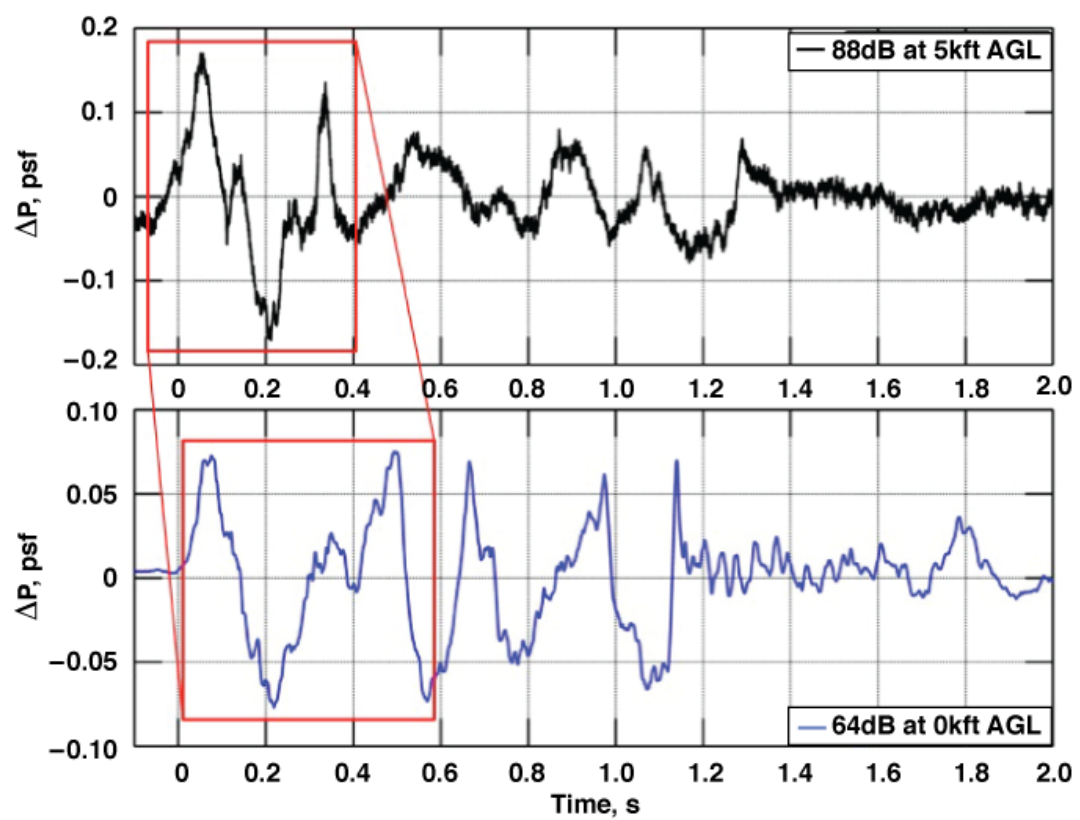

Figure 22. Comparison between midfield and ground level shadow zone measurements (flight 2, pass 1).

\section{Conclusions}

Analysis of the FaINT Mach cutoff data produced several notable results. PL $L_{S E L}$ has been suggested as a metric for further study of sonic boom signatures of the type experienced in the Mach cutoff shadow zone. SEL metrics have been shown to be more consistent metrics than other sonic boom metrics commonly used for studying $\mathrm{N}$-waves, such as $\mathrm{PL}_{70}$.

FaINT demonstrated the ability to record sonic boom measurements over 5000-ft (1524.0-m) AGL and below $\mathrm{Z}_{\mathrm{CO}}$, using a motorglider. The measurements show similar pressure signature characteristics with those recorded on the ground. Such a database will provide a working reference as shadow zone acoustic numerical solutions are developed and validated. 
The parameter $\left(\mathrm{M}_{\mathrm{T}}-\mathrm{M}\right)$ was found to be useful when analyzing shadow zone acoustics when flying since it is directly related to $\mathrm{Z}_{\mathrm{CO}}$, and because it is more intrinsic to conventional flight operations to monitor flight conditions in terms of speed rather than $\mathrm{Z}_{\mathrm{CO}}$. Data showed a direct correlation between PL $\mathrm{SEL}_{\mathrm{SEO}} \mathrm{Z}_{\mathrm{CO}}$ and $\left(\mathrm{M}_{\mathrm{T}}-\mathrm{M}\right)$, with $\mathrm{PL}_{\mathrm{SEL}} / \mathrm{Z}_{\mathrm{CO}}$ decreasing with increase of $\left(\mathrm{M}_{\mathrm{T}}-\mathrm{M}\right)$.

An empirical relationship between airplane flight conditions and sound exposure levels in the shadow zone was derived (Eq. (8)). The empirical relationship is an exponential function, which is consistent with evanescent wave theory. The paper also demonstrated the need and ability to correlate measured sonic booms below $\mathrm{Z}_{\mathrm{CO}}$ with the precise time it was generated by the airplane. This concept may not have been emphasized in previous studies, and accurate Mach cutoff analysis cannot be done without doing so. The importance is due to the sensitivity of Mach cutoff parameters to flight conditions. Incorrect estimates of $\left(\mathrm{M}_{\mathrm{T}}-\mathrm{M}\right)$ on the order of only 0.005 can result in a difference of $+/-15 \mathrm{~dB}$ or more, based on Eq. (8).

The FaINT dataset was used to validate the Haglund ${ }^{15}$ safe cutoff altitude theory. Test cases with $\mathrm{Z}_{\mathrm{CO}}$ greater than one $\Delta \mathrm{Z}_{\mathrm{S}}$ above the ground showed maximum $\Delta \mathrm{P}$ and $\mathrm{PL}$ SEL of 0.09 and $68 \mathrm{~dB}$ respectively. These values are low enough to be considered of "relatively small intensity," as defined by Haglund. ${ }^{15}$

Monte Carlo simulations were performed as a sensitivity analysis. It was shown that variations in atmospheric conditions on the order of 3 knots in wind speed, 10-degrees in wind direction, and 3-degrees Celsius in temperature, could result in PLSEL of over $20 \mathrm{~dB}$ higher than the mean. The simulations also showed that adding realistic perturbations in flight conditions could result in a much wider, harder-to-predict dispersion of PLSEL.

\section{References}

${ }^{1}$ Dowling, A. P., and Ffowcs Williams, J. E., Sound and Sources of Sound, Ellis Horwood Limited, Chichester, England, 1989, p. 91.

${ }^{2}$ Maglieri, D. J., Bobbitt, P. J., Plotkin, K. J., Shepherd, K. P., Coen, P. G., and Richwine, D. M., “Sonic Boom: Six Decades of Research,” NASA/SP-2014-622, 2014.

${ }^{3}$ Coulouvrat, F., "Sonic Boom in the Shadow Zone: A Geometrical Theory of Diffraction," Journal of the Acoustical Society of America, Vol. 111, No. 1, 2002, pp. 499-508.

${ }^{4}$ Haglund, G. T., and Kane, E. J., "Flight Test Measurement and Analysis of Sonic Boom Phenomena Near the Shock Wave Extremity," NASA CR-2167, 1973.

${ }^{5}$ Maglieri, D. J., Hilton, D. A., Huckel, V., Henderson, H. R., and McLeod, N. J., "Measurements of Sonic Boom Signatures from Flights at Cutoff Mach Number,” NASA SP-255, 1970, pp. 243-254.

${ }^{6}$ Salamone, J. A. III, Sparrow, V. W., Plotkin, K. J., and Coward, R., "SCAMP: Solution of the Lossy Nonlinear Tricomi Equation for Sonic Boom Focusing," AIAA 2013-0935, 2013.

${ }^{7}$ Stevens, S. S., "Perceived Level of Noise by Mark VII and Decibels (E)," Journal of the Acoustical Society of America, Vol. 51, No. 2, 1972, pp. 575-601.

${ }^{8}$ Cliatt, L. J. II, Haering, E. A. Jr., Arnac, S. R., and Hill, M. A., "Lateral Cutoff Analysis and Results from NASA's Farfield Investigation of No-boom Thresholds," NASA/TM-2016-218850, 2016.

${ }^{9}$ Brusniak, L., Underbrink, J. R., and Stoker, R. W., “Acoustic Imaging of Aircraft Noise Sources Using Large Aperture Phased Arrays," AIAA-2006-2715, 2006.

${ }^{10}$ Haering, E. A., Jr., Cliatt, L. J. II, Bunce, T. J., Gabrielson, T. B., Sparrow, V. W., and Locey, L.L., "Initial Results from the Variable Intensity Sonic Boom Propagation Database," AIAA-2008-3034, 2008.

${ }^{11}$ Cliatt, L. J. II, Haering, E. A., Jr., Jones, T. P., Waggoner, E. R., Flattery, A. K., and Wiley, S. L., “A Flight Research Overview of WSPR, a Pilot Project for Sonic Boom Community Response," AIAA 2014-2268, 2014.

${ }^{12}$ Page, J. A., Plotkin, K. J., and Wilmer, C., PCBoom Version 6.6 Technical Reference and User Manual, Wyle Report WR 10$10,2009$.

${ }^{13}$ Shepherd, K. P., and B. M. Sullivan, “A Loudness Calculation Procedure Applied to Shaped Sonic Booms,” NASA TP-3134, 1991.

${ }^{14}$ International Organization for Standards, “Acoustics - Description, Measurement and Assessment of Environmental Noise," ISO 1996-2, 2007.

${ }^{15}$ Haglund, G. T., and Kane, E. J., "Analysis of Sonic Boom Measurements Near Shock Wave Extremities for Flight Near Mach 1.0 and for Airplane Accelerations," NASA CR-2417, 1974. 


\section{Appendix A: Mach Cutoff Measurements and Calculations}

Table 3 lists the average computed key $\mathrm{M}_{\mathrm{CO}}$ parameters discussed in this paper for each of the FaINT $\mathrm{M}_{\mathrm{CO}}$ flight passes. Results from flight 6 were excluded because it was performed during conditions of high wind, making the microphone data problematic to analyze.

Table 3. Mach cutoff measurements and calculations.

\begin{tabular}{|c|c|c|c|c|c|c|c|}
\hline $\begin{array}{l}\text { Flight } \\
\text { number }\end{array}$ & $\begin{array}{c}\text { Pass } \\
\text { number }\end{array}$ & $\mathrm{M}_{\mathrm{T}}-\mathrm{M}$ & $\begin{array}{c}\mathrm{Z}_{\mathrm{CO}} \\
\mathrm{ft} \text { AGL }\end{array}$ & $\begin{array}{c}\mathrm{PL}_{\mathrm{SEL}} / \mathrm{Z}_{\mathrm{co}} \\
\mathrm{dB} / \mathrm{ft}\end{array}$ & $\frac{\left(Z_{\mathrm{CO}}-Z_{\mathrm{S}}\right)}{\Delta Z_{\mathrm{S}}}$ & $\begin{array}{l}\Delta \mathrm{P} \\
\mathrm{psf}\end{array}$ & $\begin{array}{c}\text { PLSEL, } \\
\text { dB }\end{array}$ \\
\hline \multirow{6}{*}{1} & 1 & 0.004507 & 10 & 15.12542 & -2.5 & 0.62 & 91 \\
\hline & 2 & 0.013432 & 5260 & 0.01284 & 0.5 & 0.07 & 68 \\
\hline & 3 & 0.024532 & 7290 & 0.00910 & 1.8 & 0.07 & 66 \\
\hline & 4 & 0.025725 & 7430 & 0.00933 & 1.9 & 0.10 & 69 \\
\hline & 5 & 0.011748 & 4720 & 0.01346 & 0.2 & 0.05 & 64 \\
\hline & 6 & -0.000925 & 1290 & 0.06310 & -1.9 & 0.22 & 81 \\
\hline \multirow{6}{*}{2} & 1 & 0.026728 & 8440 & 0.00758 & 1.0 & 0.08 & 64 \\
\hline & 2 & 0.001245 & 3890 & 0.01910 & -1.9 & 0.24 & 74 \\
\hline & 3 & 0.018382 & 6660 & 0.01020 & -0.2 & 0.11 & 68 \\
\hline & 4 & 0.025560 & 8290 & 0.00710 & 0.9 & 0.03 & 59 \\
\hline & 5 & 0.021766 & 7190 & 0.00850 & 0.2 & 0.09 & 61 \\
\hline & 6 & 0.017678 & 6510 & 0.00919 & -0.3 & 0.06 & 60 \\
\hline \multirow{6}{*}{3} & 1 & 0.016286 & 4960 & 0.01314 & 0.3 & 0.09 & 65 \\
\hline & 2 & 0.017097 & 5070 & 0.01239 & 0.4 & 0.07 & 63 \\
\hline & 3 & 0.001667 & 3220 & 0.02463 & -0.8 & 0.33 & 79 \\
\hline & 4 & 0.017698 & 5150 & 0.01197 & 0.4 & 0.03 & 62 \\
\hline & 5 & 0.010034 & 4140 & 0.01583 & -0.2 & 0.03 & 66 \\
\hline & 6 & 0.008703 & 3960 & 0.01545 & -0.3 & 0.03 & 61 \\
\hline \multirow{7}{*}{4} & 1 & 0.047163 & 14200 & 0.00441 & 6.8 & 0.01 & 63 \\
\hline & 2 & 0.022249 & 6520 & 0.00837 & 1.4 & 0.02 & 55 \\
\hline & 3 & 0.027549 & 6700 & 0.01012 & 1.4 & 0.01 & 68 \\
\hline & 4 & 0.033654 & 7460 & 0.00758 & 1.9 & 0.01 & 57 \\
\hline & 5 & 0.004017 & 3620 & 0.01742 & -0.5 & 0.08 & 63 \\
\hline & 6 & -0.000123 & 1780 & 0.04205 & -1.6 & 0.26 & 75 \\
\hline & 7 & 0.033931 & 7540 & 0.00728 & 2.0 & 0.01 & 55 \\
\hline \multirow{6}{*}{5} & 1 & 0.025571 & 9490 & 0.00595 & 2.1 & 0.02 & 56 \\
\hline & 2 & 0.020024 & 7010 & 0.00892 & 0.4 & 0.07 & 63 \\
\hline & 3 & 0.026920 & 9570 & 0.00616 & 2.2 & 0.03 & 59 \\
\hline & 4 & 0.022048 & 8210 & 0.00746 & 1.3 & 0.05 & 61 \\
\hline & 5 & -0.000059 & 3710 & 0.02188 & -1.6 & 0.33 & 81 \\
\hline & 6 & -0.002044 & 1600 & 0.04500 & -2.9 & 0.11 & 72 \\
\hline
\end{tabular}

